\title{
Improved Prediction of the Indian Ocean Dipole Mode by Use of Subsurface Ocean Observations ${ }^{\mathscr{O}}$
}

\author{
TAKESHI DOI \\ Application Laboratory/Japan Agency for Marine-Earth Science and Technology, Yokohama, Japan \\ ANDREA STORTO \\ Centro Euro-Mediterraneo per i Cambiamenti Climatici, Bologna, Italy \\ SWADHIN K. BEHERA \\ Application Laboratory/Japan Agency for Marine-Earth Science and Technology, Yokohama, Japan \\ ANTONIO NAVARRA \\ Centro Euro-Mediterraneo per i Cambiamenti Climatici, Bologna, Italy \\ TOSHIO YAMAGATA \\ Application Laboratory/Japan Agency for Marine-Earth Science and Technology, Yokohama, Japan
}

(Manuscript received 27 December 2016, in final form 30 May 2017)

\begin{abstract}
The numerical seasonal prediction system using the Scale Interaction Experiment-Frontier version 1 (SINTEX-F) ocean-atmosphere coupled model has so far demonstrated a good performance for prediction of the Indian Ocean dipole mode (IOD) despite the fact that the system adopts a relatively simple initialization scheme based on nudging only the sea surface temperature (SST). However, it is to be expected that the system is not sufficient to capture in detail the subsurface oceanic precondition. Therefore, the authors have introduced a new three-dimensional variational ocean data assimilation (3DVAR) method that takes threedimensional observed ocean temperature and salinity into account. Since the new system has successfully improved IOD predictions, the present study is showing that the ocean observational efforts in the tropical Indian Ocean are decisive for improvement of the IOD predictions and may have a large impact on important socioeconomic activities, particularly in the Indian Ocean rim countries.
\end{abstract}

\section{Introduction}

The Indian Ocean dipole mode (IOD), an air-sea coupled climate mode in the tropical Indian Ocean, is characterized by a dipole structure along the equator in both ocean and atmospheric anomalies: sea surface temperature (SST), upper ocean heat content, sea level pressure (SLP), outgoing longwave radiation (OLR), rainfall, and so on (Saji et al. 1999; Webster et al. 1999;

Supplemental information related to this paper is available at the Journals Online website: https://dx.doi.org/10.1175/ JCLI-D-16-0915.s1.

Corresponding author: Takeshi Doi, takeshi.doi@jamstec.go.jp
Yamagata et al. 2004; Schott et al. 2009). The positive phase of the IOD develops as a warmer-than-normal SST off East Africa and a colder-than-normal SST off Sumatra. The IOD is now known to have serious impacts on the world climate, similar to El Niño-Southern Oscillation (ENSO) in the tropical Pacific [see Yamagata et al. (2016) for a recent review]. In particular, Indian Ocean rim countries such as Australia, India, and East African countries are influenced by the IOD more strongly than by ENSO (Ashok et al. 2001, 2003; Saji and Yamagata 2003; Guan and Yamagata 2003; Behera and Yamagata 2003; Enomoto et al. 2003; Yamagata et al. 2004; Cai et al. 2005; Behera et al. 2005; Chan et al. 2008; Yuan et al. 2009). It is shown that IOD may even influence ENSO occurrence (Behera and 
Yamagata 2003; Luo et al. 2010; Izumo et al. 2010; Yuan et al. 2011). Therefore, the seasonal predictability of the IOD is important not only for understanding basic climate dynamics, but also for crucial societal applications in agriculture, fishery, marine ecosystem, human health, natural disasters, etc. (e.g., Yuan and Yamagata 2015; Abram et al. 2003; Nakamura et al. 2009; Takaya et al. 2014; Hashizume et al. 2012; Cai et al. 2009).

Iizuka et al. (2000) successfully simulated the IOD for the first time, using an ocean-atmosphere coupled general circulation model (CGCM) without flux correction. Thereafter, several studies challenged to predict the IOD occurrence and also its global influence dynamically based on CGCMs (Wajsowicz 2005, 2007; Luo et al. 2007, 2008a; Song et al. 2008; Zhao and Hendon 2009; Hendon and Wang 2010; Shi et al. 2012; Yang et al. 2015; Zhu et al. 2015a; Liu et al. 2017; Feng et al. 2017). Those studies found that the IOD could be predicted one season ahead. Some strong IOD events were actually predicted a few seasons ahead (Luo et al. 2008a). However, some of the state-of-the-art CGCMs, such as the NCEP Climate Forecast System version 2 (CFSv2), still lack the skill to be significantly better than persistence in predicting IOD events as seen in 1982-2009 hindcast results (Zhu et al. 2015a). Event-to-event diversity that affects the IOD prediction may be rooted in the difference of development mechanisms as discussed recently by Tanizaki et al. (2017). Moreover, some IOD events appear to be triggered by intraseasonal disturbances and have low potential predictability, while some other events that co-occur with ENSO are apparently more predictable (Song et al. 2008; Hendon and Wang 2010; Yang et al. 2015).

The Scale Interaction Experiment-Frontier version 1 (SINTEX-F1) prediction system, based on a fully coupled global ocean-atmosphere circulation model developed under the EU-Japan collaborative framework (Luo et al. 2005a,b), has so far demonstrated a worldleading performance for prediction of ENSO (Luo et al. 2008b; Jin et al. 2008). This system has also successfully predicted several IOD events a few seasons ahead (Luo et al. 2007, 2008a). Analyzing past predictions, event by event, it emerges that the SINTEX-F1 system was able to predict the 1994 positive event well, but the 1997 event was not predicted well (Luo et al. 2007). The 2006 positive IOD event, the biggest event in the recent 15 years, was predicted three seasons ahead and the successive unusual 2007 positive IOD event was also predicted successfully one season ahead (Luo et al. 2008a; Behera et al. 2008). Based on those scientific outcomes, we have been providing the real-time forecast of IOD every month since 2005 (see http://www.jamstec. go.jp/frcgc/research/d1/iod/e/seasonal/outlook.html).
However, the SINTEX-F1 completely failed to predict the 2012 positive IOD event (e.g., Doi et al. 2016; Tanizaki et al. 2017). This big failure was the first since 2005 when the SINTEX-F prediction model became operational. On the other hand, the positive IOD event that occurred in 2015 was successfully predicted one season ahead.

Although the SINTEX-F1 system is skillful in predicting most IOD event occurrences reasonably well, there is much room for improvement, particularly in the CGCM configuration and the ocean initialization scheme. To address those, a revised CGCM, a highresolution version with a dynamical sea ice model called SINTEX-F2, has been developed (Doi et al. 2016). This seems to have improved the prediction skill in the subtropics, although we note that the influence of resolution on model simulations could be very model dependent (e.g., Navarra et al. 2008; Zhu et al. 2015b). However, we cannot find much improvement in the tropics. The SINTEX-F1/F2 system adopted a relatively simple SST nudging scheme for the initialization (Luo et al. 2005a; Doi et al. 2016). Although it is one of the simplest approaches, it generates balanced initial conditions between the atmosphere and oceans and reduces the initialization shock in seasonal prediction. Although the SST nudging scheme can capture interannual variations of the tropical Pacific thermocline in the SINTEX-F1 CGCM (Luo et al. 2005a), it is not suitable to properly initialize subsurface oceanic conditions of the tropical Indian and Atlantic Oceans and extratropical oceans because air-sea coupling is weaker there relative to the tropical Pacific (e.g., Kumar et al. 2013, 2014; Kohyama and Tozuka 2016). To improve the prediction, we have adopted a scheme based on a three-dimensional variational ocean data assimilation method (3DVAR) by use of subsurface observations, to complement the aforementioned SST nudging scheme. We note that the SST nudging scheme cannot resolve high-frequency ocean variability associated with the Madden-Julian oscillation (MJO) and westerly wind bursts, which may have strong impacts on the timing of initiation and termination of ENSO and IOD events (McPhaden 1999, 2004; Rao and Yamagata 2004; Rao et al. 2009). They may be initialized indirectly by the 3DVAR scheme when the ocean observation system captures those signals.

In this paper, we explore how the prediction skill of the IOD is improved by the development of the model and the ocean initialization for the SINTEX-F systems. In section 2, we briefly review the seasonal prediction systems and the new ocean initialization scheme with 3DVAR correction. We then evaluate the new initialization scheme in section 3. In section 4, the IOD prediction skill is discussed using the retrospective forecast 
experiments for the period from 1983 to 2015. Section 6 is a brief summary with discussion about future research.

\section{Numerical seasonal prediction systems and observational datasets}

\section{a. SINTEX-F1 seasonal prediction system}

The SINTEX-F1 fully coupled global ocean-atmosphere GCM has been used for the Application Laboratory (APL)/JAMSTEC seasonal prediction system (Luo et al. 2005a,b). On the basis of the original European SINTEX models (Gualdi et al. 2003a; Guilyardi et al. 2003), the SINTEX-F1 CGCM has been developed. The atmospheric component (ECHAM4) has a resolution of T106 $\left(1.125^{\circ}\right)$ with 19 vertical levels (Roeckner et al. 1996). The oceanic component (OPA8) has a relatively coarse resolution of $2^{\circ} \times 2^{\circ}$ Mercator horizontal mesh but with a tropical refinement up to $0.58^{\circ}$ in the meridional direction (Madec et al. 1998). It has 31 vertical levels from the surface to the bottom with finer resolution of $10 \mathrm{~m}$ from the sea surface to $110-\mathrm{m}$ depth. The coupling information, including SST, surface momentum, and heat and water fluxes, is exchanged every $2 \mathrm{~h}$ without any corrections by means of the Ocean Atmosphere Sea Ice Soil (OASIS) 2 coupler (Valcke et al. 2000). Sea ice cover is relaxed toward observed monthly climatology via the ocean component. Initial conditions for prediction are generated using a relatively simple SST nudging initialization scheme (Luo et al. 2005a). Model SSTs are strongly nudged toward daily observations in a coupled model at three restoring time of 1,2, and 3 days since 1 January 1982 using the weekly NOAA OISSTv2 (Reynolds et al. 2002). Specified SSTs force the surface atmospheric variability through the atmospheric component, which in turn forces subsurface ocean variability through the oceanic component. Therefore, the fidelity of the initialization will largely depend on the model performance. This scheme has also been successfully applied in near-term climate predictions (Keenlyside et al. 2005, 2008; Zhu et al. 2015c, 2017; Müller et al. 2014). In addition, model-coupling physics is perturbed in three different ways to treat the interaction between surface wind stress and ocean surface current (Luo et al. 2005b). The ensemble prediction system with the SINTEX-F consists of nine ensemble members that combine the three different SST nudging time scales with three different schemes of wind stress and currents interactions, accounting for uncertainties in both initial conditions and model coupling physics. More details about the prediction system are available in Luo et al. (2005a). Hereinafter, we called this system the F1 system.

\section{b. SINTEX-F2 prediction system}

The SINTEX-F2 coupled model, a high-resolution and upgraded version with a dynamical sea ice model, has been developed to resolve several physical processes, particularly relatively small-scale phenomena in the ocean (Masson et al. 2012; Sasaki et al. 2013a). The atmospheric component (ECHAM5) has a horizontal resolution of T106 (as in the SINTEX-F1 model) with 31 vertical levels (Roeckner et al. 2003). The oceanic component (OPA9) has a horizontal resolution of a $0.5^{\circ} \times 0.5^{\circ}$ tripolar grid (known as the ORCA05 configuration), with 31 vertical levels as similar to the SINTEX-F1 system (Madec 2008). While no sea ice model is incorporated in the SINTEX-F1 system, the dynamical sea ice model of the Louvain-la-Neuve Sea Ice Model (LIM) version 2 (LIM2) (Fichefet and Morales Maqueda 1997) is embedded in the SINTEXF2 system. The atmospheric and oceanic fluxes, including SST, sea ice fraction, freshwater, surface heat, surface current, and momentum fluxes, are exchanged every $2 \mathrm{~h}$ with no flux correction by means of the Ocean Atmosphere Sea Ice Soil, version 3 (OASIS3) coupler (Valcke et al. 2004) as in the F1 system. The momentum flux of the ocean surface current is directly passed to the atmosphere. Several versions of the SINTEX-F2 coupled model are already used for various climate studies, for example, seasonal to interannual variations in both the tropics and extratropics, the Indian summer monsoon, tropical cyclones, etc. (Masson et al. 2012; Joseph et al. 2012; Terray et al. 2012; Sasaki et al. 2012, 2013a,b; Nagura et al. 2013; Morioka et al. 2013; Sasaki et al. 2014; Prodhomme et al. 2014; Morioka et al. 2014; Sasaki et al. 2015; Prodhomme et al. 2015; Morioka et al. 2015). The SINTEX-F2 coupled model partly reduced model biases in climatological fields relative to the SINTEX-F1 coupled model, particularly in the southern subtropical Indian Ocean (e.g., Morioka et al. 2014; Doi et al. 2016). Similar to the SINTEX-F1 prediction system, the SST nudging scheme is adopted for the initialization using the high-resolution $\left(0.25^{\circ} \times 0.25^{\circ}\right)$ daily NOAA OISSTv2 analyses (Reynolds et al. 2007). In the SST nudging run with the SINTEX-F2, the specified SSTs force the surface atmospheric variability through the atmospheric component, which in turn forces subsurface ocean and sea ice variability through the oceanic component including the dynamical ice model. Then, initial conditions for the ice model are also provided through the SST nudging scheme. In addition, considering large uncertainties in ocean vertical mixing estimates, ocean physics is perturbed in two different ways by considering or neglecting ocean vertical mixing induced by small vertical-scale structures (SVSs) within 
TABLE 1. Major differences between the F1, the F2, and the F2-3DVAR systems.

\begin{tabular}{|c|c|c|c|c|c|c|}
\hline & AGCM & OGCM & Coupling & Sea ice model & Ensemble size & Initialization \\
\hline F1 system & $\begin{array}{l}\text { ECHAM4.6 } \\
\text { T106L19 }\end{array}$ & $\begin{array}{l}\text { OPA } 8.2 \\
2^{\circ} \times\left(0.5^{\circ}-2^{\circ}\right) \mathrm{L} 31\end{array}$ & $\begin{array}{l}\text { Every } 2 \mathrm{~h} \\
\text { No flux correction }\end{array}$ & No & 9 & SST nudging \\
\hline F2 system & $\begin{array}{l}\text { ECHAM5 } \\
\text { T106L31 }\end{array}$ & $\begin{array}{l}\text { OPA9 } \\
0.5^{\circ} \times 0.5^{\circ} \mathrm{L} 31\end{array}$ & Same as F1 & LIM2 & 6 & Same as F1 \\
\hline $\begin{array}{l}\text { F2-3DVAR } \\
\text { system }\end{array}$ & $\begin{array}{l}\text { ECHAM5 } \\
\text { T106L31 }\end{array}$ & $\begin{array}{l}\text { OPA9 } \\
0.5^{\circ} \times 0.5^{\circ} \mathrm{L} 31\end{array}$ & Same as F1 & LIM2 & 6 & $\begin{array}{l}\text { SST nudging with 3DVAR } \\
\text { ocean assimilation }\end{array}$ \\
\hline
\end{tabular}

and above the equatorial thermocline (Sasaki et al. 2012, 2013a). Therefore, the six-member SINTEX-F2 ensemble prediction system takes into consideration uncertainties of both initial conditions and model physics to some extent. More details and the overview of the prediction skill based on the retrospective forecasts experiments during the period from 2000 to 2014 are discussed by Doi et al. (2016). Hereafter, this system is called the F2 system.

\section{c. New initialization scheme with the $3 D V A R$}

In the new scheme, OGCM SSTs are strongly nudged toward the observations in the coupled run continuously from January 1982, which is similar to the simple SST nudging scheme used in the F2 system. In addition, 3DVAR correction is conducted every first day of each month using the Met Office Hadley Centre EN4 profile data of subsurface ocean temperature and salinity observation (Good et al. 2013). The set of in situ observations consists of all types of ocean profiling instruments that provide temperature and salinity (when available) from the expendable bathythermographs (XBTs), mooring buoys, sea stations, Argo floats, etc. XBT data are used with the fall rate correction from Gouretski and Reseghetti (2010). The details of the 3DVAR scheme used here such as formulation and specification of observation and background error covariances are shown in Storto et al. (2011, 2014). A fully nonlinear observation operator is used only once to compute the initial departures by employing the background fields closer to the observation time [first guess at appropriate time (FGAT)]. In our formulation, only temperature and salinity are corrected after a 3DVAR/ FGAT assimilation step; altimetry sea surface height observations are not assimilated. The assimilation time window is 10 days, using all types of ocean profiling instruments that provide temperature and (if available) salinity (e.g., ARGO floats, moored buoys, etc.) included in the temporal range of \pm 5 days before and after the assimilation time. The assimilation frequency is monthly (i.e., the assimilation time window is centered at the end of each month). We have implemented this new initialization scheme in each of the six ensemble members of the F2 system. Although there is no perturbation in the 3DVAR scheme, the different SST nudging time scales embedded in our system imply uncertainty in the initial conditions, which is similar to the F1 and F2 systems. Hereinafter, we call this the F23DVAR system. Table 1 highlights the main aspects of those three systems.

\section{d. Skill assessment and reference datasets}

To compare the prediction skill among the F1, the F2, and the F2-3DVAR systems, we have conducted retrospective forecasts with 12-month lead time on the first day of each month from January 1983 to December 2015 by using the Earth Simulator (for a system overview, see http://www.jamstec.go.jp/es/en/index.html). We have calculated prediction anomalies by removing the model mean climate drifts at each lead time a posteriori using the retrospective forecast outputs during the period from 1983 to 2015. Also, we have calculated the ensemble mean simply by averaging results from nine (six) ensemble members for the F1 system (the F2 and the F2-3DVAR systems).

In this paper, we mainly use anomaly correlation coefficients (ACCs) and root-mean-square errors normalized by the standard deviation of the observation (nRMSEs) as deterministic prediction skill scores of the phase and amplitude variations. For a skillful prediction, the ACC needs to be higher than the persistence (lag autocorrelation) and the nRMSE needs to be less than one.

To evaluate the prediction results, we have used the NOAA OISSTv2 (Reynolds et al. 2002) for SST, the NCEP-NCAR reanalysis data (Kalnay et al. 1996) for atmospheric variables [2-m air temperature, surface 10-m wind speed, outgoing longwave radiation (OLR), and geopotential height at $200 \mathrm{hPa}$, the CPC Merged Analysis of Precipitation (CMAP) dataset (Xie and Arkin 1997) for rainfall, and the EN4 gridded objective analyses (Good et al. 2013) for ocean subsurface temperature anomalies. In addition, we used the NCEP GODAS ocean reanalysis (Behringer et al. 1998) for ocean subsurface temperature and the ERA-Interim reanalysis (Dee et al. 2011) for 10-m wind to elucidate 
the uncertainty among the observational and the reanalysis data. Monthly climatologies are calculated by averaging monthly data over the period from 1983 to 2015 , and then anomalies are defined as deviations from them.

\section{Initialization skill for the subsurface ocean}

To explore how the subsurface ocean condition is initialized, we compare the two initialization schemes using the SINTEX-F2. We first focus on May 1997, the preconditioning season before the strongest positive IOD in the last 30 years (see Figs. S1 and S2 in the supplemental material). The new initialization scheme with $3 \mathrm{DVAR}$ proves to be much better in capturing the tropical Indian Ocean subsurface condition relative to the SST nudging scheme, although the observational network was very coarse at that time (e.g., McPhaden et al. 1998). The 3DVAR scheme removes the subsurface cold biases of the SST nudging scheme in the mean state, and deepens the thermocline in the whole tropics. Interestingly, there is a disagreement in the anomalies of the eastern equatorial Indian Ocean between the EN4 gridded analysis and the GODAS reanalysis; a cold subsurface temperature anomaly is seen in the eastern equatorial Indian Ocean in the EN4 data, while the subsurface temperature below $100 \mathrm{~m}$ is anomalously warm in the GODAS data (Figs. S1b,d). Also, the $20^{\circ} \mathrm{C}$ isothermal depth (D20) in the GODAS data is deeper in the western and the eastern equatorial Indian Ocean, which is not seen in the EN4 (Fig. S2b). The disagreement may result from a lack of some subsurface ocean observation and the ocean model biases rooted in the GODAS reanalysis. The SST nudging scheme shows an unrealistic zonal gradient of the subsurface temperature anomaly in $60^{\circ}$ and $100^{\circ} \mathrm{E}$ around 20-100-m depth compared to that of both the EN4 and the GODAS data. This is partly improved by the 3DVAR scheme (Figs. S1f,h).

The interannual variations of the $20^{\circ} \mathrm{C}$ isothermal depth anomalies (D20A) along the equator in the Indian Ocean during the period from 1983 to 2015 are shown in Fig. 1 (Fig. S3 shows that for the whole equatorial region). At a glance, we see that almost all IOD events that occurred in the considered period are successfully assimilated by both the schemes, although the amplitudes in the F2-3DVAR system are much closer to both the EN4 objective analysis and the GODAS reanalysis. To further compare the skill between the two initialization schemes, we have calculated ACCs for D20A for May of 1983-2015 using the EN4 analysis as the reference (Figs. 2a,c). The condition in May is known to be important for preconditioning most IOD events (e.g.,
Horii et al. 2008). The skill is high over the tropical Pacific in both schemes. Even so, compared to the simple SST nudging scheme, the new scheme with 3DVAR correction performs better over the tropical Indian Ocean, the tropical Atlantic, and the subtropics. This feature is also mostly seen when we use the GODAS reanalysis as the reference, except for the region off Java and Sumatra. Note that the improvement by the 3DVAR scheme is more clearly seen over the period of 1999-2015 than the period of 1983-98 (Fig. S4). This is probably due to greater constraint of the model toward the EN4, which has larger number of available (assimilated) observations. Such improvement in the subsurface ocean initialization is expected to improve the IOD prediction skill significantly.

\section{Prediction skill for the IOD}

\section{a. Statistical skill scores}

We here study prediction skills of the Indian Ocean dipole mode index (DMI): the SST anomaly (SSTA) difference between the western pole off East Africa $\left(10^{\circ} \mathrm{S}-10^{\circ} \mathrm{N}, 50^{\circ}-70^{\circ} \mathrm{E}\right)$ and the eastern pole off Sumatra $\left(10^{\circ} \mathrm{S}-0^{\circ}, 90^{\circ}-110^{\circ} \mathrm{E}\right)$, as defined by Saji et al. (1999). Since the usual IOD event peaks in SeptemberNovember (SON), we focus on the DMI averaged for SON (DMI_SON) and its prediction from 1 June of each year (Fig. 3a). We also study the prediction skill of Niño3.4 , one of the most popular indices of ENSO, which is defined as the SST anomalies averaged over the domain of $5^{\circ} \mathrm{S}-5^{\circ} \mathrm{N}, 170^{\circ}-120^{\circ} \mathrm{W}$ (Fig. 3b). Although most ENSO events mature in boreal winter, we focus on the Niño-3.4 averaged over June-August (Niño-3.4_JJA) here. This is because it is suggested that the Niño-3.4_JJA prediction may help the DMI_SON prediction (e.g., Song et al. 2008). As seen in Fig. 3a, the pure IOD event in 1994 is predicted almost perfectly in magnitude by the F2-3DVAR system, although the F1 system also successfully predicts $80 \%$ of the amplitude. The F2 system captures only about a half of the amplitude. Regarding the strongest IOD event in 1997, however, all of the three systems predict only $30 \%$ of the amplitude. Regarding the 2006 pure positive event, the F1 and the F2-3DVAR systems predict almost one-half of the observed amplitude, while the F2 system fails even to predict the occurrence. The amplitude of the 2015 positive event is predicted almost perfectly by the F2 and the F2-3DVAR systems, while the F1 system overestimates by about $30 \%$. The 1998 negative event is well predicted by the F2-3DVAR system, whereas the F2 (F1) system overestimates (underestimates) the amplitude by about $30 \%$. The 2010 negative event is predicted 
D20A [m] along $2^{\circ} \mathrm{S}-2^{\circ} \mathrm{N}$ ave.

(a) EN4 analysis

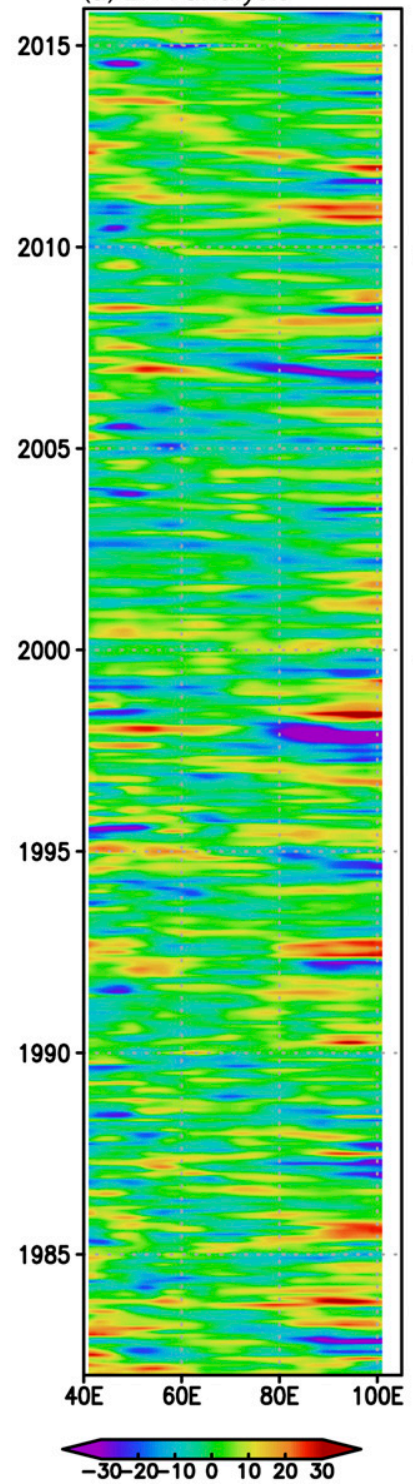

(b) GODAS reanalysis

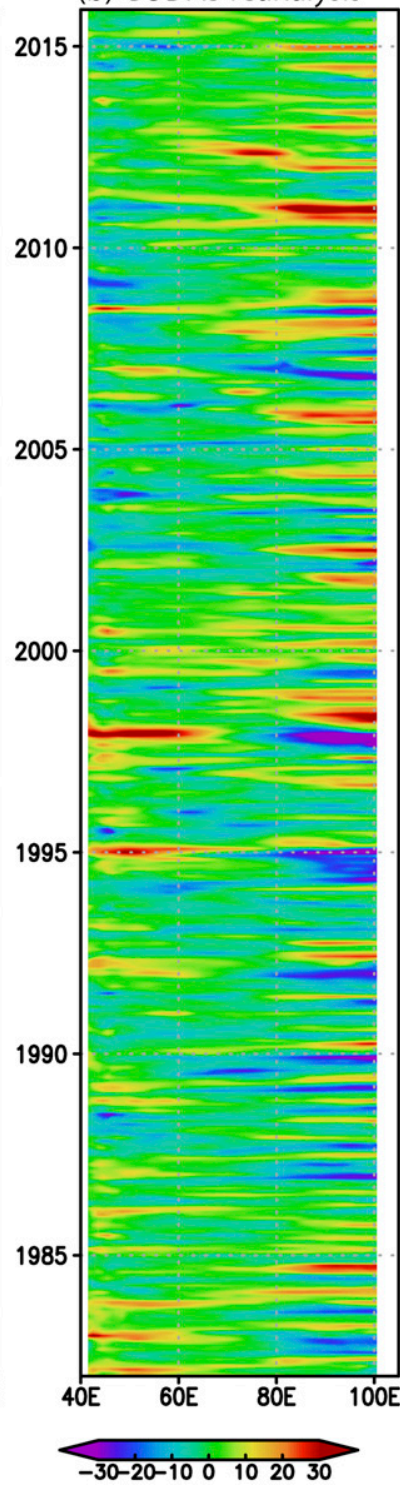

(c) SST-nudging

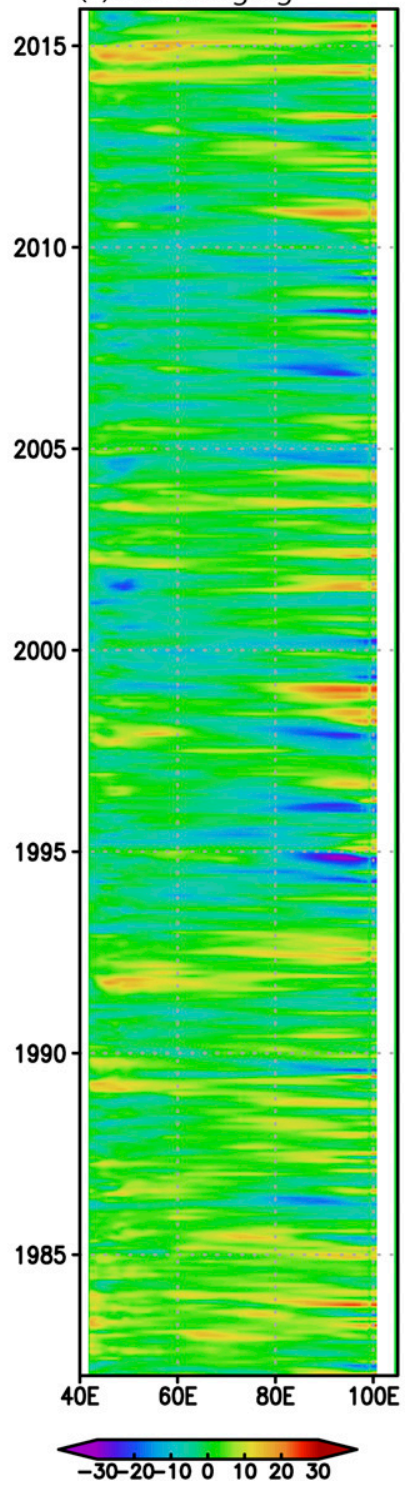

(d) SST-nudging with 3DVAR

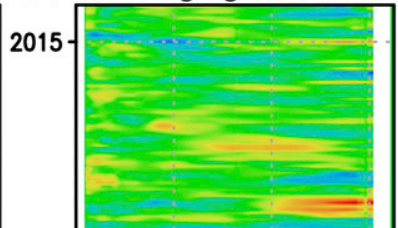

2010

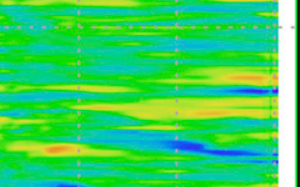

2005

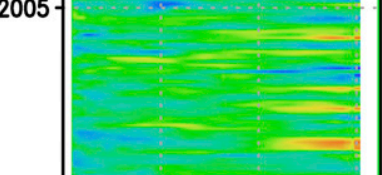

2000

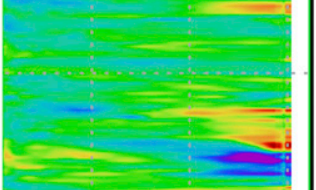

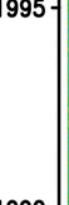

1990

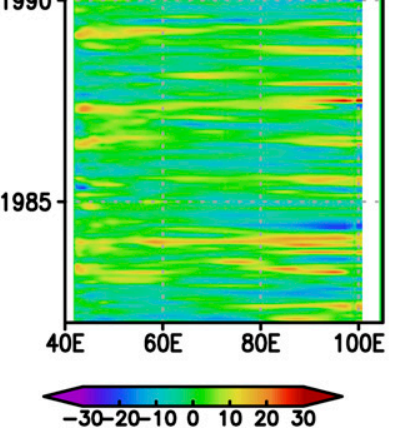

FIG. 1. Interannual variations of the $20^{\circ} \mathrm{C}$ isothermal depth anomalies (D20A) along the equator $\left(2^{\circ} \mathrm{N}-2^{\circ} \mathrm{S}\right.$ average) in $1983-2015$ (m) from (a) the EN4 gridded objective analysis and (b) the GODAS reanalysis, and the model outputs by (c) the SST nudging scheme (six-ensemble mean with the F2 system) and (d) the new initialization scheme with 3DVAR correction (six-ensemble mean with the F2-3DVAR system). Positive (negative) values show deeper (shallower) than normal.

by the F2 and the F2-3DVAR systems, although they capture only about $50 \%$ of the amplitude. The F1 system even predicts an unrealistic positive event.

The overall ACC skill scores are shown in Table 2. Since the F2-3DVAR system shows the ACC beyond the persistence during 1983-2015 (although the difference is not statistically significant), we may say that the F2-3DVAR system is skillful in predicting the DMI_SON from the 1 June initialization. The difference in ACCs between the F2 system and the F2-3DVAR system is about 0.2 (Table 2), which is due to the new initialization scheme. This difference is statistically significant above $80 \%$ significance level based on one-sided test of the Fisher $z$ transformation. This improvement is also seen for the two periods of 1983-98 and 1999-2015 (Table 2). Although the F2 system is not statistically skillful above $80 \%$ significance level in predicting the IOD in the latter period, the skill of the F2-3DVAR system is statistically significant above $95 \%$ significance level for the period. We note that the persistence and the prediction skill are 
ACC for D20A in May in 1983-2015
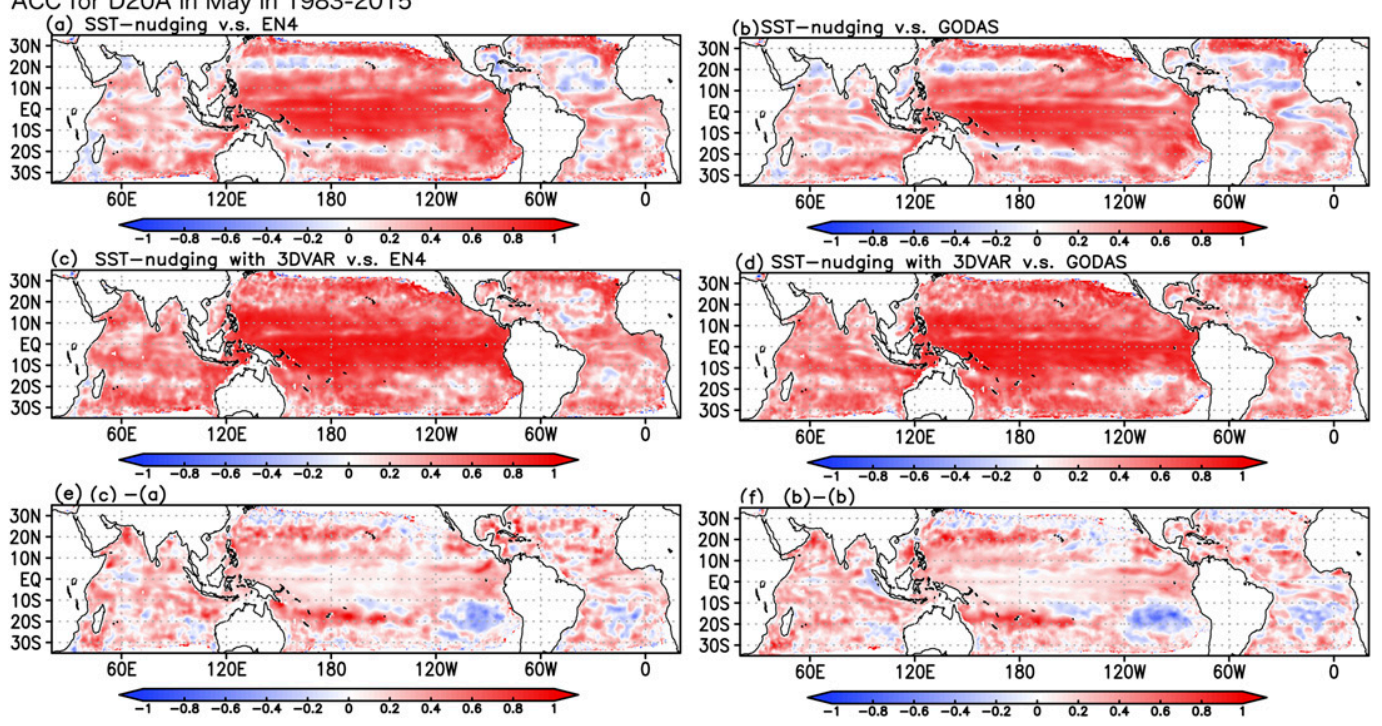

FIG. 2. (a) Horizontal map of anomaly correlation coefficients (ACCs) in D20A between the EN4 gridded objective analyses and the model outputs by the SST nudging scheme (six-ensemble mean with the F2 system) for May of 1983-2015. (b) As in (a), but for the ACCs between the GODAS reanalysis and the model outputs by the SST nudging scheme. (c) As in (a), but for the model outputs by the new initialization scheme with 3DVAR correction (six-ensemble mean with the F2-3DVAR system). (d) As in (c), but for the ACCs between the GODAS reanalysis and the model outputs by the new initialization scheme. (e),(f) Results for (c) minus (a) and for (d) minus (b), respectively.

lower in the latter period. These results based on the ACC are also consistent with that based on the nRMSE. As shown in Table 3, the new initialization scheme with the F2-3DVAR system reduced the nRMSE of the F2 system by about 0.3 for all three periods, which are statistically significant above $90 \%$ significance level based on a $t$ test.

Regarding the prediction of the Niño-3.4_JJA, all three systems show high skill, although the performance of the F2 system is slightly lower compared to the other two (the difference is not statistically significant above $80 \%$ significance level). The performance of the F23DVAR system is almost same as that of the F1 system, which showed the world-leading skill of Niño-3.4 prediction among the dynamical prediction models (Jin et al. 2008). These are also seen in nRMSE (Table 3). Therefore, we may conclude that the F2-3DVAR system preserves the high-prediction skill of the ENSO events as compared to that of the SINTEX-F1.

Horizontal maps of ACC skill scores for predicting 2-m air-temperature and rainfall in SON from the 1 June initialization are shown in Fig. 4 (see Fig. S5 for the global map). We find significant improvement in the prediction for 2-m air temperature in the F2 system as compared to that in F1 system over central Africa, the western pole of the DMI, the Bay of Bengal, Japan, the Sea of Japan, the Kuroshio-Oyashio Extension region, and southeastern Australia. The F2-3DVAR system, compared to the F2 system, shows much improved prediction skill over central Africa, the western and eastern poles of the DMI, the Bay of Bengal, and the Tibetan Plateau. This is due to the change of the ocean subsurface initialization from the simple SST nudging to the 3DVAR correction. However, we do not find much difference among the three systems in the rainfall prediction. We need to improve atmospheric responses, particularly moist processes and teleconnection patterns related to IOD and ENSO. The improvements by the new initialization scheme are also seen in the horizontal maps of nRMSE (Fig. S6). In particular, nRMSE in the western poles of the DMI is improved more than that in the eastern pole.

\section{b. 1997 strongest positive event}

The 1997 IOD event is one of the strongest events observed so far. It is also known to have co-occurred with one of the strongest El Niño periods. Here we focus on this particular event. As shown in Fig. 5, the F23DVAR system is much more skillful in predicting the development phase during JJA. While only one member of the F1 (F2) system predicted the DMI above one standard deviation during JJA, five out of six (about $80 \%$ ) ensemble members of the F2-3DVAR system predicted the DMI above one standard deviation. This is 
(a) DMI_SON $\left({ }^{\circ} \mathrm{C}\right)$

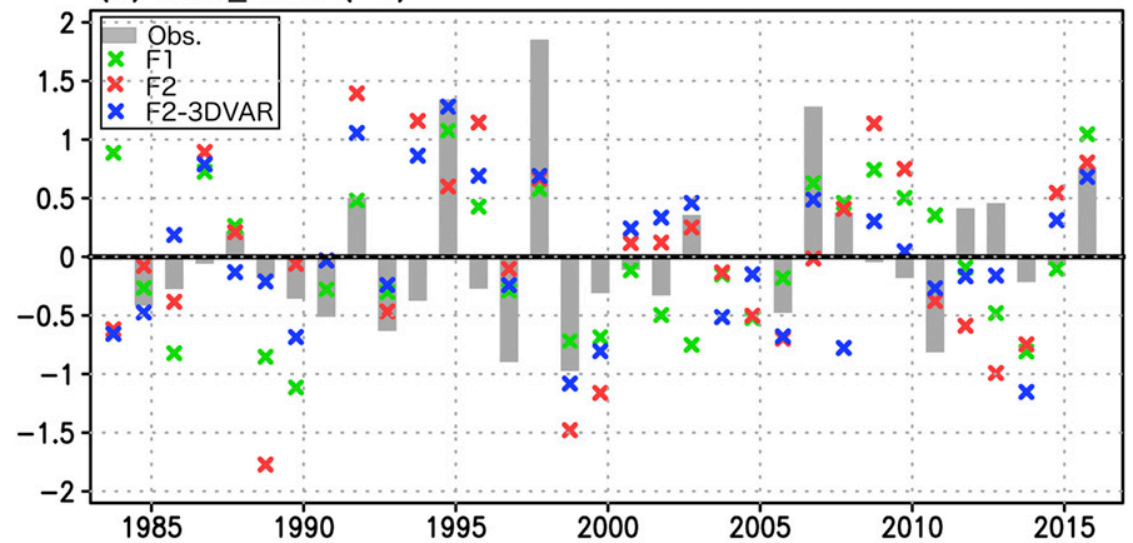

(b) Nino34_JJA $\left({ }^{\circ} \mathrm{C}\right)$

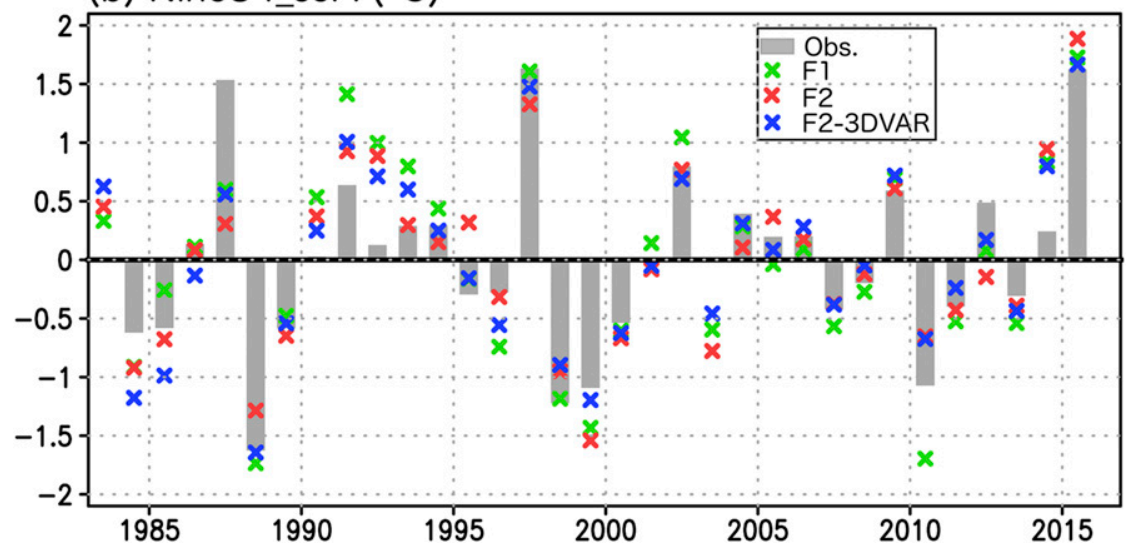

FIG. 3. (a) Time series of DMI_SON $\left({ }^{\circ} \mathrm{C}\right)$ from observation (gray bar), the ensemble mean prediction from the 1 June initialization with the F1 system (green X), the F2 system (red X), and the F2-3DVAR system (blue X). (b) As in (a), but for Niño-3.4_JJA.

reflected in the ensemble mean and the F2-3DVAR system predicts about $80 \%$ of the observed JJA value, while the F1 and the F2 systems fail to capture the evolution. Nevertheless, the F2-3DVAR system underestimates the DMI in the peak season of SON 1997 and explains only about $25 \%$ of the observation, which is almost the same as that in the F1 and the F2 systems.

Figure 6 shows the horizontal maps of D20A, SSTA, and $10-\mathrm{m}$ surface wind speed anomalies in the precondition phase of May, the development phase of JJA,

TABLE 2. ACCs for the DMI_SON and Nino-3.4_JJA between observation and ensemble mean prediction from the 1 June initialization for the periods of 1983-2015, 1983-98, and 1999-2015. The boldface font indicates values beyond the persistence (skillful). As the ensemble size is different between the F1 and F2 system - the F1 has 9 members while the F2 and the F2-3DVAR systems have 6 memberswe also have chosen 6 of 9 ensemble members in the F1 system for making the subgroups and conducted the same analysis. The ACCs of the best and the worst skill subgroups of the F1 system are noted in parentheses. The last column shows F2-3DVAR minus F2.

\begin{tabular}{lccccc}
\hline \hline & Persistent & F1 system & F2 system & F2-3DVAR system & F2-3DVAR minus F2 \\
\hline DMI_SON & & & & & \\
1983-2015 & 0.50 & $0.47(0.37-\mathbf{0 . 5 4})$ & 0.34 & $\mathbf{0 . 5 3}$ & +0.19 \\
1983-98 & 0.57 & $0.57(0.42-\mathbf{0 . 6 9})$ & 0.43 & $\mathbf{0 . 6 2}$ & +0.19 \\
1999-2015 & 0.42 & $0.34(0.25-0.39)$ & 0.21 & $\mathbf{0 . 4 3}$ & +0.22 \\
Niño-3.4_JJA & & & & $\mathbf{0 . 9 0}$ & +0.05 \\
1983-2015 & 0.68 & $\mathbf{0 . 9 0}(\mathbf{0 . 8 7}-\mathbf{0 . 9 3})$ & $\mathbf{0 . 8 5}$ & $\mathbf{0 . 8 8}$ & +0.04 \\
1983-98 & 0.64 & $\mathbf{0 . 8 8}(\mathbf{0 . 8 4}-\mathbf{0 . 9 2})$ & $\mathbf{0 . 8 4}$ & $\mathbf{0 . 9 4}$ & +0.05 \\
1999-2015 & 0.83 & $\mathbf{0 . 9 5}(\mathbf{0 . 9 4 - 0 . 9 6 )}$ & $\mathbf{0 . 8 9}$ & & \\
\hline
\end{tabular}


TABLE 3. As in Table 2, but for nRMSE $\left({ }^{\circ} \mathrm{C}\right)$. The bold font indicates values below one (skillful).

\begin{tabular}{lcccc}
\hline & F1 system & F2 system & F2-3DVAR system & F2-3DVAR minus F2 \\
\hline DMI_SON & & & & \\
1983-2015 & $1.03(1.11-1.00)$ & 1.31 & $\mathbf{0 . 9 7}$ & -0.34 \\
$1983-98$ & $\mathbf{0 . 9 2}(1.07-\mathbf{- 0 . 7 9})$ & 1.21 & $\mathbf{0 . 8 8}$ & -0.33 \\
1999-2015 & $1.22(1.31-1.22)$ & 1.51 & & -0.37 \\
Niño-3.4_JJA & & & $\mathbf{0 . 4 5}$ & -0.10 \\
1983-2015 & $\mathbf{0 . 5 3}(\mathbf{0 . 5 8 - 0 . 4 3 )}$ & $\mathbf{0 . 5 4}$ & $\mathbf{0 . 4 9}$ & -0.05 \\
1983-98 & $\mathbf{0 . 5 5}(\mathbf{0 . 6 1 - 0 . 4 5 )}$ & $\mathbf{0 . 5 4}$ & $\mathbf{0 . 3 5}$ & -0.19 \\
1999-2015 & $\mathbf{0 . 4 8}(\mathbf{0 . 4 9 - 0 . 4 8 )}$ & $\mathbf{0 . 5 4}$ & & \\
\hline
\end{tabular}

and the maximum peak phase of SON. As shown in Figs. $6 \mathrm{~b}$ and $6 \mathrm{c}, \mathrm{D} 20 \mathrm{~A}$ is very consistent with the winds in JJA and SON 1997, which reflects the Bjerknes-type airsea coupling (Bjerknes 1964) as discussed in Saji et al. (1999). In contrast, the D20A from the EN4 analysis is not consistent with the wind anomaly from the NCEPNCAR reanalysis data for May 1997 (Fig. 6a). Figure 6d is the same as Fig. 6a, but for D20A in the NCEP GODAS reanalysis and 10-m wind in the ERA-Interim reanalysis. We can see a disagreement in D20A off Java and Sumatra between the EN4 gridded analysis and the GODAS reanalysis as discussed in section 3. This wind anomaly of May 1997 was not captured correctly by the F1, F2, and F2-3DVAR systems (Figs. 6g,j,m). Therefore, in order to properly initiate the wind-induced subsurface anomalies, the 3DVAR ocean assimilation is necessary: this will help to correctly initialize the subsurface ocean of the tropical Indian Ocean. The F23DVAR system initializes well the positive zonal gradient of D20A in the tropical Indian Ocean in May 1997 as seen in the EN4 gridded objective analyses (Fig. 6m), while the F1 and the F2 systems do not (Figs. 6g,j). This may be the reason why the F2-3DVAR system successfully predicts the development of the positive zonal gradient of SSTA and D20A, and the anomalous westerly in JJA 1997 in contrast to the F1 and the F2 systems. The F1 system underestimated the zonal dipole structure of the subsurface ocean in SON 1997. The F2 system partly improved it, although the underestimation is not fully recovered. The F2-3DVAR system is the closest to the observation and the reanalysis datasets among the three prediction systems. Particularly, the F2-3DVAR system predicts the warm SST anomaly off Somalia and in the Arabian Sea, and the thermocline dome over the southwestern tropical Indian Ocean, the Seychelles Dome (Yokoi et al. 2008; Tozuka et al. 2010; Yokoi et al. 2012), much better than the F1 and the F2 systems. However, the colder-than-normal water in the eastern pole extends westward unrealistically and intrudes into the western pole of the IOD in the F2-3DVAR system. This may cause the F2-3DVAR system to continue to underestimate the positive SST anomaly in the western pole. As a result, the mature phase of DMI is rather underestimated by the F2-3DVAR system. This model bias is also seen in the F1, the F2, and other state-of-theart climate models (Cai and Cowan 2013). Fixing those model biases will lead to further improvement in the IOD prediction (Gualdi et al. 2003b; Wajsowicz 2005).

The significant improvement in predicting the SSTA over the tropical Indian Ocean in JJA 1997 may have also influenced the atmosphere response. As shown in Fig. 7, the F2-3DVAR system successfully predicts the dipole structure of rainfall anomalies over the tropical Indian Ocean, while the F2 system captures only the drier eastern pole. The F1 system almost fails to predict the dipole structure of rainfall anomalies.

The IOD is known to be related to the climate variability over East Asia and Australia. There are several teleconnection patterns related to the IOD: a pattern shifted slightly westward similar to the original PacificJapan (PJ) pattern (Nitta 1987), the Silk Road pattern (Guan and Yamagata 2003; Enomoto et al. 2003), the monsoon-desert mechanism pattern (Rodwell and Hoskins 1996), and the Rossby wave train pattern in the southeastern part of Australia (Ashok et al. 2003; Cai et al. 2005). However, all of three systems fail to predict the warmer-than-normal conditions over the Far East in JJA 1997. The anomalous fields of OLR, geopotential height at $200 \mathrm{hPa}$, and wave-activity flux at $200 \mathrm{hPa}$ (Takaya and Nakamura 2001) are not well predicted by any of the three systems (Fig. 7). We need to deepen our understanding of these atmospheric responses and teleconnection patterns.

The DMI prediction for other positive (negative) events with the amplitude above one standard deviation in SON is shown in Fig. S7 (Fig. S8). Compared to the 1997 positive event mentioned above, the differences among the F1, the F2, and the F2-3DVAR systems are not so clear. Among those events, we shed light on the 2012 positive event. The F1 system predicted the negative phase of the IOD (Fig. S7c). In reality, the positive DMI developed rapidly from July 2012 and matured in 
ACC for SON from Jun. 1 ini. (Left:2mAirTemp, Right:Rainfall)

(a) F1

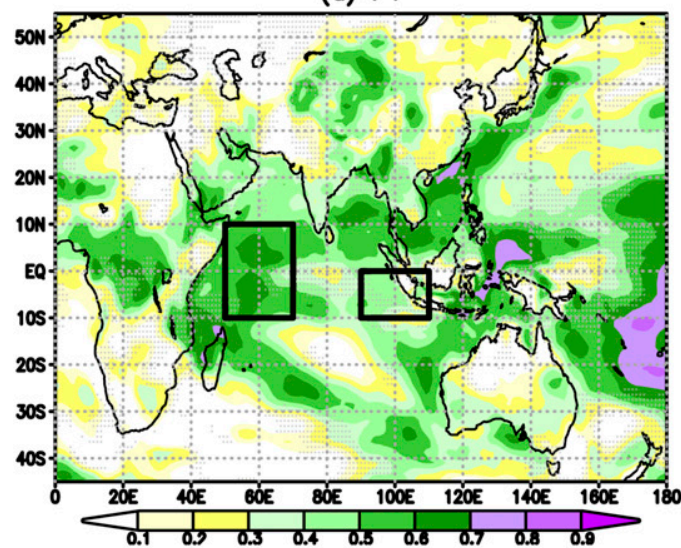

(c) F2

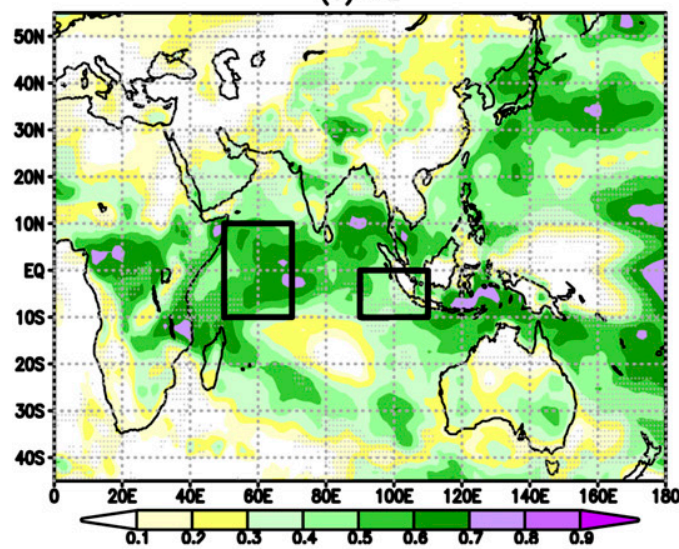

(e) F2_3DVAR

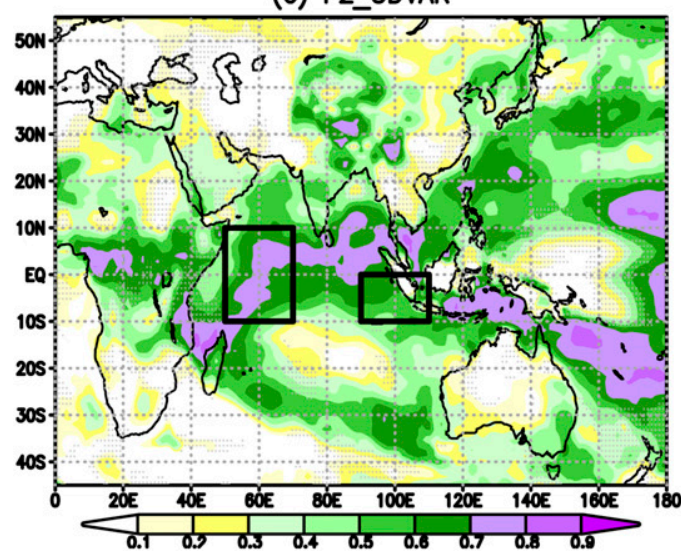

(b) $\mathrm{F} 1$

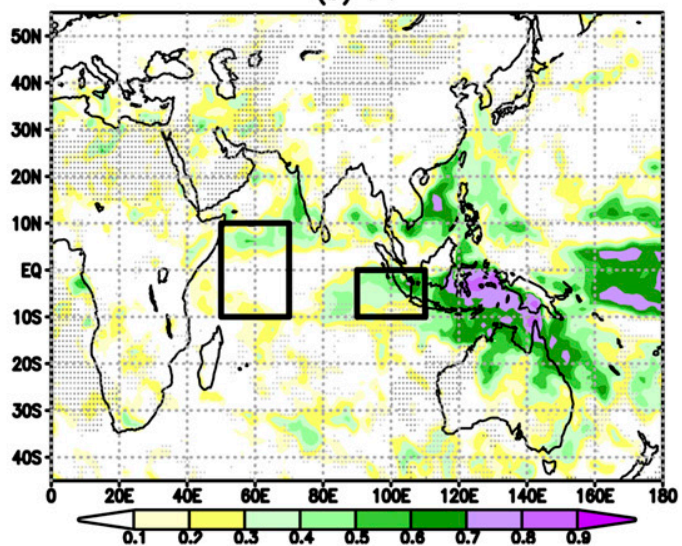

(d) F2

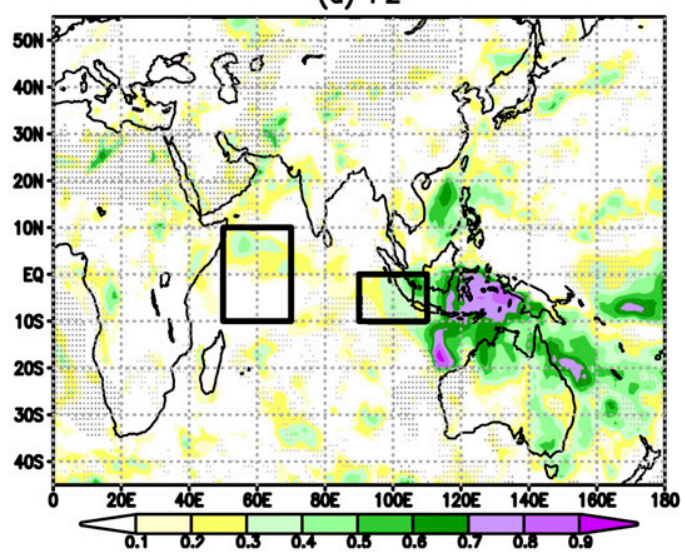

(f) F2_3DVAR

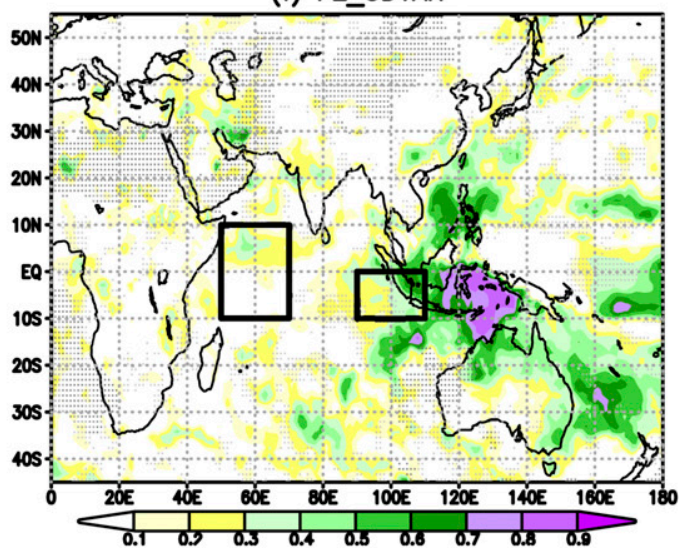

FIG. 4. (a) Anomaly correlation coefficient (ACC) for SON 2-m air temperature between the NCEP-NCAR reanalysis data and the prediction initialized on every 1 June of each year with the F1 system (nine-ensemble mean) in 1983-2015. Dark shading indicates where the ACC is below the persistence. (b) As in (a), but for rainfall between the CMAP and the prediction. Dark shading is where the ACC is below the persistence or the standard deviation of the interannual variability of the observation in 1983-2015 is below $0.2 \mathrm{~mm} \mathrm{day}^{-1}$. (c),(d) As in (a),(b), but for the F2 system. (e),(f) As in (a),(b), but for the F2-3DVAR system. The DMI regions are shown by black boxes. 


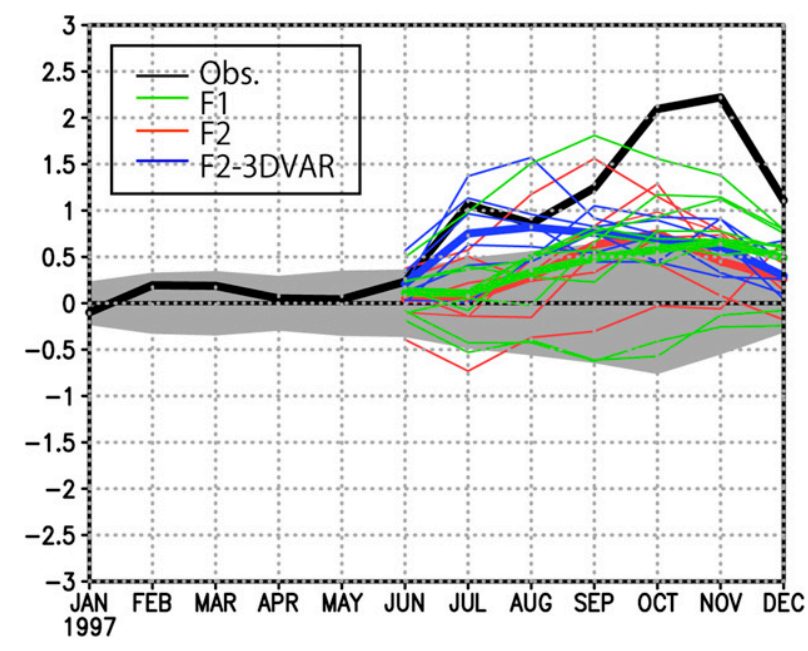

FIG. 5. Monthly DMI in $1997\left({ }^{\circ} \mathrm{C}\right)$ from the observational data of NOAA OISSTv2 (black) and the prediction from the 1 Jun 1997 initialization with the F1 system (thin green: each ensemble member, thick green: ensemble mean), the F2 system (thin red: each ensemble member, thick red: ensemble mean), and the F23DVAR system (thin blue: each ensemble member, thick blue: ensemble mean). Gray shading denotes the range between -1 and 1 seasonal standard deviation (STD) of the observation.

August 2012. Its magnitude was above $1^{\circ} \mathrm{C}$, about twice as large as the observed standard deviation and was almost same as that observed in August of the 1997 positive event. Then, it started to decay in September and disappeared during SON 2012. This course of evolution is quite unique as a conventional IOD event peaks in SON. All of the three systems fail to predict this unusual positive event and predict a negative event. Although the F2-3DVAR system has generally improved the F2 system, it was unable to predict the development of the 2012 positive event. Actually, almost all members of the U.S. National Multi-Model Ensemble (NMME; http://www.cpc.ncep.noaa.gov/products/NMME/) also failed to predict the 2012 positive IOD event one season ahead, except for the GFDL seasonal prediction system (http://www.cpc.ncep.noaa.gov/products/NMME/ archive/2012040800/current/tmpsfc_Seas3.html). Therefore, model comparisons and further analysis of this event may contribute to our understanding of IOD development/termination and thereby help us improve IOD predictions. We note that the unique formation of the anomalous SST in the 2012 positive IOD event has been recently discussed by Tanizaki et al. (2017).

\section{Summary and discussion}

The SINTEX-F model has shown high skill in predicting tropical climate variations in the past decade.
However, the prediction of the Indian Ocean dipole mode is not entirely satisfactory and we have described in this paper a possible improvement. We have adopted two simple methods: 1) the model upgrade from the F1 to the F2 system, a high-resolution version with a dynamical sea ice model, and 2) the improvement of the ocean initialization scheme by including a 3DVAR scheme that assimilates subsurface observational profile data (the F2-3DVAR system). As a result some success has been demonstrated. We have found that the F23DVAR system is the best to predict IOD events among the three F1, F2, and F2-3DVAR systems we discussed, and also preserves the high-prediction skill of the ENSO events as compared to the SINTEX-F1. The teleconnection patterns and combinations of ENSO and IOD events are known to be the most important sources of seasonal predictability over the Pacific and Indian Ocean rim countries (e.g., Behera et al. 2006). In such a research stream, improved prediction of the IOD teleconnections is necessary, together with that of the ENSO teleconnections. To achieve this, both improvement of the atmospheric and oceanic models and enhancement of the ensemble system in terms of ensemble generation strategy and ensemble size may be needed. As shown in the present work, the subsurface ocean precondition is proved to be crucial in affecting the predictive skill. Therefore neglecting the 3DVAR assimilation of subsurface ocean data in the F2 system leads to less predictive skills for the DMI and the Niño3.4. An interesting aspect is that the F2 system shows lower predictive skills than those of the F1 system despite the efforts at model improvement (Table 2). It is worth discussing why the prediction skill of the DMI and the Niño-3.4 is less for the F2 than for the F1, although the difference is not statistically significant above the $80 \%$ significance level based on a one-sided test of the Fisher $z$ transformation. Since the F1 and the F2 systems show almost similar skills in initializing the D20A field via the SST nudging scheme (figure not shown), the differences are mainly due to the inherent model biases. The mean SST predicted by the F2 system in the tropical Pacific and Indian Oceans is colder than that by the F1 system (Doi et al. 2016). This cold bias may weaken the air-sea coupling and contaminate the predictions for the DMI and the Niño-3.4 by the F2 system. We note here that Doi et al. (2016) have found that the prediction of the subtropical conditions is better for the F2 than for the F1. We need further study about the interaction between the subtropics and the tropics using the F1 and the F2. Also, it might be partly due to the inclusion of unconstrained smaller-scale processes that follow the increase of resolution in the ocean component and/or the differences in the ensemble generation strategy 
Indian Ocean Dipole in 1997

Anomalous SST(shaded),D20(contour) and UV10m(vector)
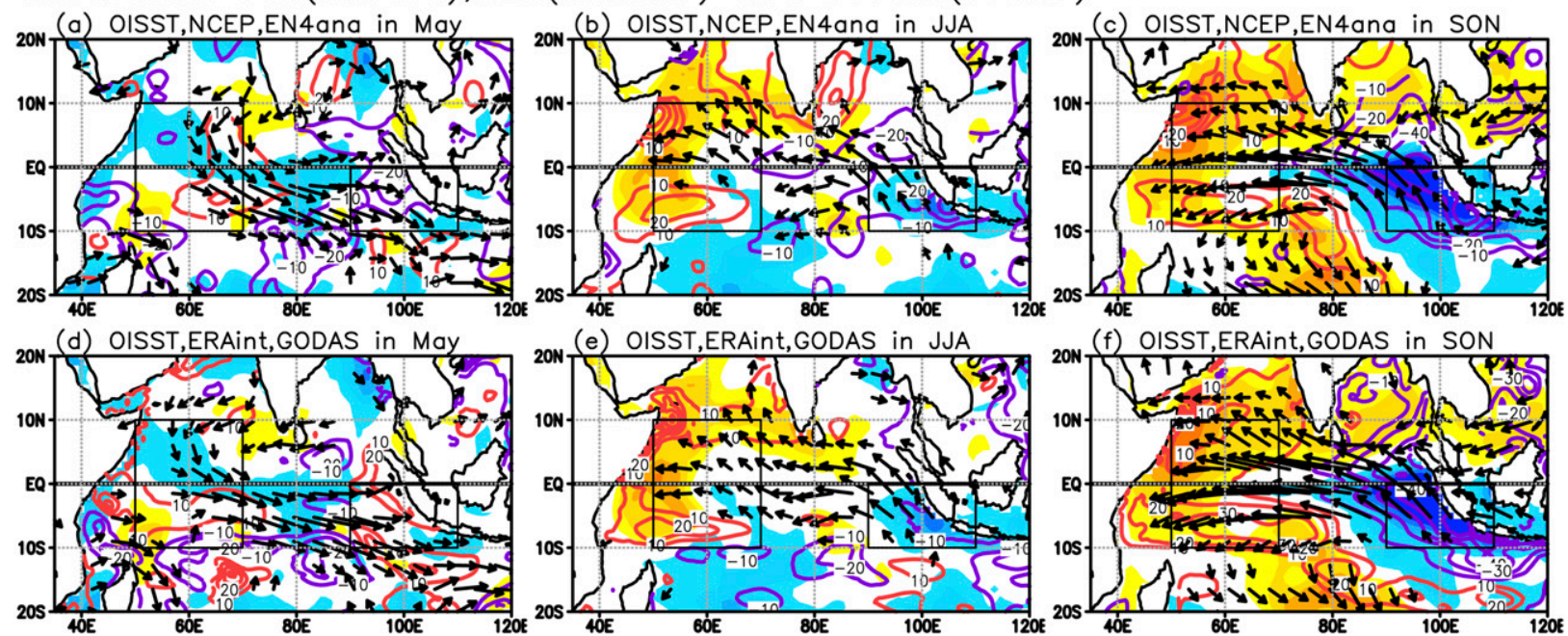

(g) SST-nudging with F1 in May
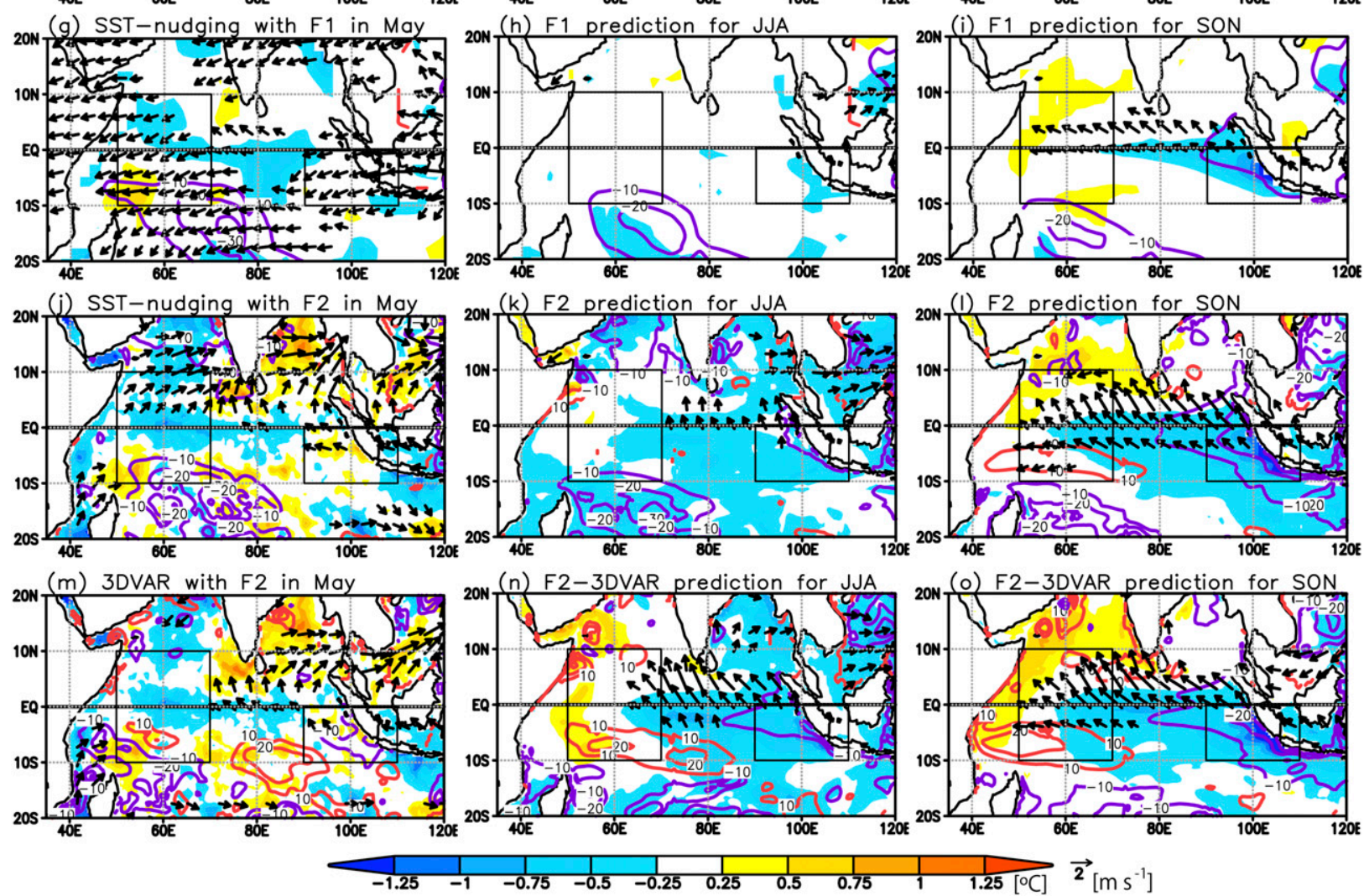

FIG. 6. Anomalous D20 (m, contour), SST $\left({ }^{\circ} \mathrm{C}\right.$, shaded), and 10-m surface wind speed ( $\mathrm{m} \mathrm{s}^{-1}$, vector) for (a) May, (b) JJA, and (c) SON 1997 from the observation (the NOAA OISST for SST; the EN4 analysis for D20) and the NCEP-NCAR reanalysis data for 10-m wind. The DMI regions are shown by black boxes. When wind speed is less than $1 \mathrm{~m} \mathrm{~s}^{-1}$, the vectors are masked out. (d)-(f) As in (a)-(c), but for the NCEP GODAS reanalysis for D20 and the ERA-Interim reanalysis for 10-m wind. (g) As in (a), but for the model outputs by the SST nudging scheme (nine-ensemble mean with the F1 system). (h),(i) As in (b),(c), but for the ensemble mean prediction from the 1 Jun 1997 initialization with the F1 system. (j)-(l) As in (g)-(i), but for the six-ensemble mean with the F2 system. (m)-(o) As in (g)-(i), but for the six-ensemble mean with the F2-3DVAR system. 
(a) Obs. in JJA1997

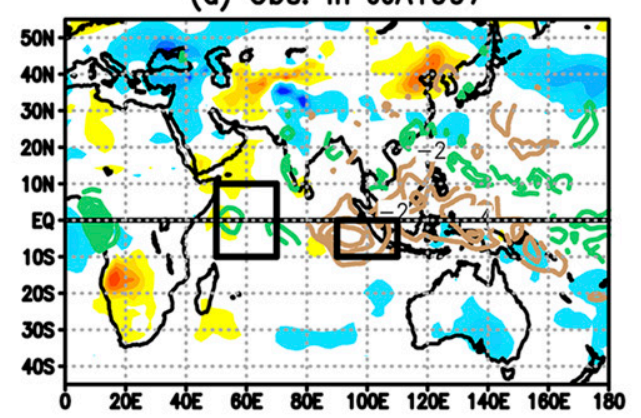

(b) F1 prediction for JJA1997 from Jun1st

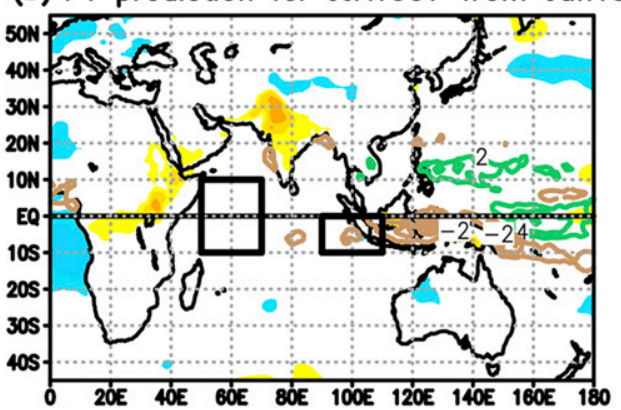

(c) F2 prediction for JJA1997 from Jun1st 20N (e) NCEP/NCAR Re. in JJA1997
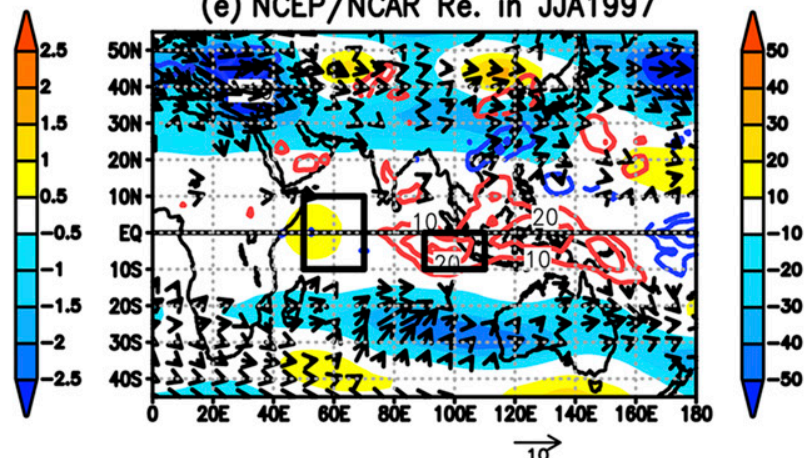

(f) F1 prediction for JJA1997 from Jun1st
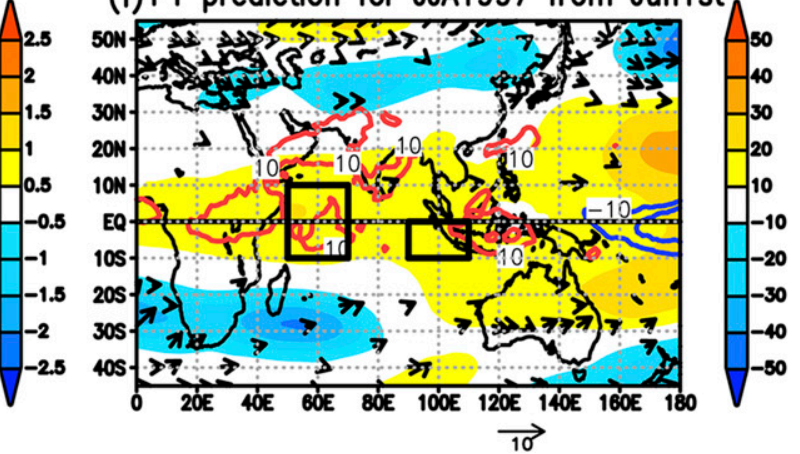

(g)F2 prediction for JJA1997 from Jun1st
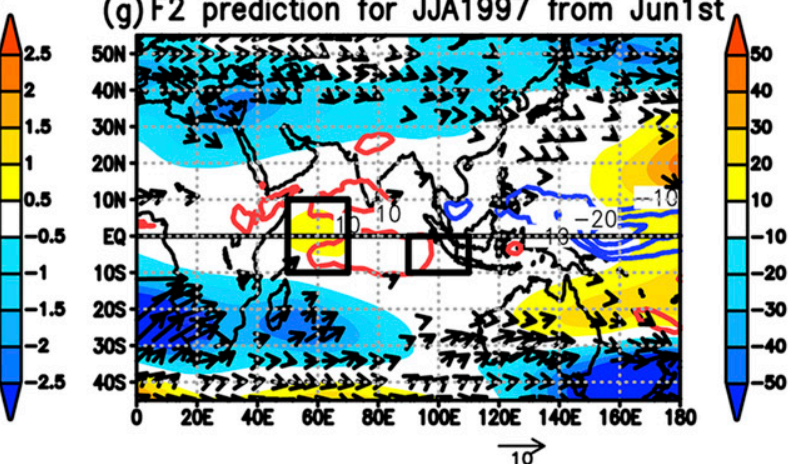

(d) F2-3DVAR prediction for JJA1997 from Jun1st

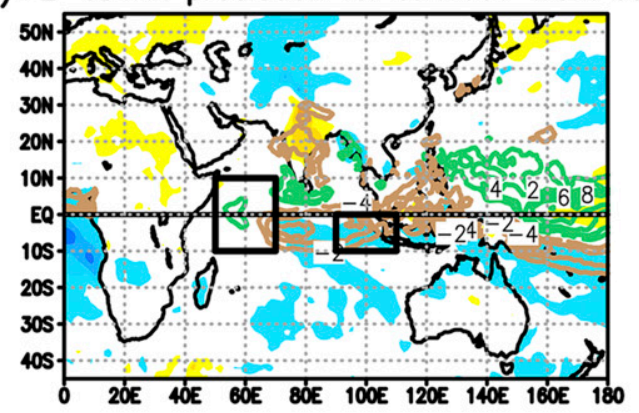

(h) F2-3DVAR prediction for JJA1997 from Jun1st
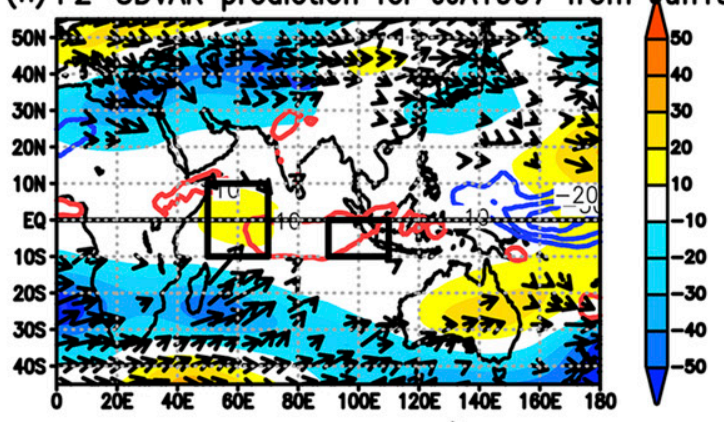

FIG. 7. (a) Anomalous rainfall (mm day ${ }^{-1}$; contour) and surface temperature $\left({ }^{\circ} \mathrm{C}\right.$; shaded) in JJA 1997 from the observation. The DMI regions are shown by black boxes. (b) As in (a), but for ensemble mean prediction from the 1 Jun 1997 initialization by the F1 system. (c) As in (b), but for the F2 system. (d) As in (b), but for the F2-3DVAR systems. (e) Anomalous OLR (W m ${ }^{-2}$; contour) and geopotential height at $200 \mathrm{hPa}\left(\mathrm{m}\right.$; shaded), and the wave activity flux (vector; $\mathrm{m}^{2} \mathrm{~s}^{-2}$ ) at $200 \mathrm{hPa}$ in JJA 1997 from the NCEP-NCAR reanalysis data. The DMI regions are also shown by black boxes. (f) As in (e), but for ensemble mean prediction from the 1 Jun 1997 initialization by the F1 system. (g) As in (f), but for the F2 system. (h) As in (f), but for the F2-3DVAR system. 
between the two systems. We note that the ensemble size is different between the F1 and F2 systems; the F1 has nine members while the F2 and the F2-3DVAR systems have six members each. We have set several subgroups of the F1 system with different combinations of six out of nine ensemble members to repeat the same analysis. The ACCs of the best and the worst skill subgroups are noted in parentheses in Table 2. Although the differences between the two subgroups related to the Niño-3.4 are almost less than 0.05 and not statistically significant above $80 \%$ significance level, there is large uncertainty in the skill related to the DMI among the ensemble members. Increasing ensemble size may improve the skill significantly. This is one of our challenges for the future.

Initializing methods for an atmosphere-ocean coupled model often rely on separate atmosphere and ocean analyses, the combination of which can leave the coupled system imbalanced at the beginning of the forecast, potentially accelerating the development of errors (Mulholland et al. 2015). One of the merits of the SST nudging scheme is in its easy generation of balanced initial conditions between atmosphere and ocean; reducing the initial shock is important during forecasts. We here check the initial shock between the SST nudging scheme and the new scheme with the 3DVAR correction for the 1997 event. Figure S9 shows the Hovmöller diagrams for daily SST and D20 along the equator for each ensemble member in the F2 and the F2-3DVAR systems. This example is from the initiation phase of May 1997 to the prediction phase of June 1997 for the 1 June initialization. The SST and D20 time series at $55^{\circ} \mathrm{E}$ on the equator are shown in Fig. S10. Here, we simply defined the initial shock as the difference between the last initialized date and the first forecast date. The SST difference at $0^{\circ}, 55^{\circ} \mathrm{E}$ is $-0.3^{\circ} \mathrm{C} \mathrm{day}^{-1}$ around the 1 June 1997 initialization with the $\mathrm{F} 2$ system, whereas it is $-0.2^{\circ} \mathrm{Cday}^{-1}$ with the $\mathrm{F} 2$ 3DVAR system. The D20 difference is $2.5 \mathrm{~m} \mathrm{day}^{-1}$ around the date with the F2 system, whereas it is $1.5 \mathrm{~m} \mathrm{day}^{-1}$ with the F2-3DVAR system. The initial shock is reduced in the F2-3DVAR system for this case. It seems important to retain the SST nudging to keep balanced initial conditions at the air-sea interface. We then check the differences in the climate drift from the 1 June initialization between the F2 and the F2-3DVAR systems (Fig. S11). As shown in Fig. S11a, the difference in the predicted DMI climatology is small. The horizontal maps of the climate drift show clear reduction of the cooling drift over the eastern Indian Ocean and the Arabian Sea in the F2-3DVAR system (Figs. S11b,c). We even find the warming drift off Somalia. We certainly need further model improvement by reducing the model mean bias to improve the IOD prediction (Gualdi et al. 2003b; Wajsowicz 2005).
The SST nudging scheme has another merit. It does not require large investments in assimilations and observations. This simplicity enables us to extend the retrospective hindcast period backward in time when the SST observational data are made available (e.g., Müller et al. 2014). Therefore, the development of the highly accurate climate prediction system with the simple SST nudging scheme will continue to be very useful. At this stage, we do not fully understand the pathway of the prediction skill in the SINTEX-F and how this can be replicated in other models with such a simple initialization scheme. Very recently, Zhu et al. (2017) showed that most capabilities of seasonal predictions from the individual NMME models could also be accomplished when adopting the SST nudging scheme. It could also be possible that a particular model configuration and model-dependent resolutions optimize the predictability. We may need further careful intercomparison including SINTEX-F and other models.

It is interesting to compare IOD predictability among the state-of-the-art prediction systems. We have adopted the NOAA/GFDL_FLORB1 12-ensemble prediction system (Vecchi et al. 2014; Jia et al. 2015), the NCAR/ CCSM4 10-ensemble prediction system (Kirtman and Min 2009), and the CCCma CanCM3 and CanCM4 10-ensemble prediction systems (http://www.cccma.ec.gc. ca/models). The reforecast outputs are obtained from Phase-II data of the North American Multi-Model Ensemble Data Access (https://www.earthsystemgrid.org/ search.html?Project=NMME) (Kirtman et al. 2014). Although there is the difference in the ensemble size among those systems (F2-3DVAR $=6$, GFDL_FLORB1 $=12$, and CCSM4 and the CanCM3/4 = 10), we have simply compared the ensemble means here. The skill of the F23DVAR system is better than that of CanCM3 and almost similar to that of CanCM4, while the skill in GFDL_ FLORB1 and NCAR CCSM4 is generally better than that of the F2-3DVAR (see Table S1 and Fig. S12). In particular, the 1997 strongest positive event and the 2012 positive event are predicted almost perfectly by GFDL_FLORB1. Those successful predictions may give us a hint to improve the IOD prediction in the other prediction systems, although the differences may be due to various reasons such as model performance, initialization scheme, ensemble size, and generation strategy. Also, there is a large eventby-event diversity for the IOD prediction among prediction systems; it is much larger compared to the ENSO prediction. This suggests the need of model intercomparison. The multimodel ensemble prediction for the DMI may be useful for societal purposes as successfully demonstrated by the multimodel ENSO forecast by the International Research Institute for Climate and Society 
(IRI) at Columbia University (Barnston et al. 2015) and the NMME (Kirtman et al. 2014). In this context, Liu et al. (2017) have recently demonstrated that the multiple model ensemble predictions show the useful skill of the IOD prediction.

The present study has shown that the ocean observations in the tropical Indian Ocean are important for improvement of the IOD prediction. RAMA mooring buoys (McPhaden et al. 2009) and Argo floats (Hosoda et al. 2008) are already shown to be quite useful and their further development is promising. In particular, the Second International Indian Ocean Expedition (IIOE-2) in 2015-20 will provide new important ocean observational data (http://www.iioe-2.incois.gov.in/\#). As shown by Feng et al. (2017), the subsurface ocean observation will reduce large uncertainty in the wintertime IOD prediction, which may allow us to do the long-time-lead prediction from boreal winter. In the F2-3DVAR, we perform assimilation once per month with a \pm 5 -day window, and we do not assimilate observations for about $2 / 3$ days of the month (only observations on 10 days each month). The assimilation configuration with monthly frequency and 10 days assimilation time window was chosen as a compromise between the number of assimilated observations, the 3DVAR assumption of observations temporally simultaneous in the analysis, and consistency with the monthly seasonal prediction system initialization. In the future, we plan to investigate in details the impact of the ocean data assimilation frequency and time window length. The F2-3DVAR system presented in this paper may be also used for partial assimilation experiments, as conducted by Observing System Experiments (OSEs) and Observing System Simulation Experiments (OSSEs), in order to evaluate the potential impacts of present and future ocean observing systems (e.g., Balmaseda and Anderson 2009; Fujii et al. 2015). Those studies are underway.

Acknowledgments. The SINTEX-F1/F2 seasonal climate prediction systems were run by the Earth Simulator at JAMSTEC. We are grateful to Drs. Wataru Sasaki, Jing-Jia Luo, Sebastian Masson, and our European colleagues of INGV/CMCC, L'OCEAN, and MPI for their contribution to developing the prototype of the systems. This research was supported by the Environment Research and Technology Development Fund (2-1405) of the Ministry of the Environment, Japan, the Japan Agency for Medical Research and Development (AMED) and Japan International Cooperation Agency (JICA) through the Science and Technology Research Partnership for Sustainable Development (SATREPS) project for iDEWS South Africa, and JSPS KAKENHI Grants 16H04047 and 16K17810.

\section{REFERENCES}

Abram, N. J., M. K. Gagan, M. T. McCulloch, J. Chappell, and W. S. Hantoro, 2003: Coral reef death during the 1997 Indian Ocean Dipole linked to Indonesian wildfires. Science, 301, 952-955, doi:10.1126/science.1083841.

Ashok, K., Z. Guan, and T. Yamagata, 2001: Impact of the Indian Ocean dipole on the decadal relationship between the Indian monsoon rainfall and ENSO. Geophys. Res. Lett., 28, 44994502, doi:10.1029/2001GL013294.

_ _ - and _ 2003: Influence of the Indian Ocean Dipole on the Australian winter rainfall. Geophys. Res. Lett., 30, 1821, doi:10.1029/2003GL017926.

Balmaseda, M., and D. Anderson, 2009: Impact of initialization strategies and observations on seasonal forecast skill. Geophys. Res. Lett., 36, L01701, doi:10.1029/2008GL035561.

Barnston, A. G., M. K. Tippett, H. M. van den Dool, and D. A. Unger, 2015: Toward an improved multimodel ENSO prediction. J. Appl. Meteor. Climatol., 54, 1579-1595, doi:10.1175/ JAMC-D-14-0188.1.

Behera, S. K., and T. Yamagata, 2003: Influence of the Indian Ocean dipole on the Southern Oscillation. J. Meteor. Soc. Japan, 81, 169-177, doi:10.2151/jmsj.81.169.

, J.-J. Luo, S. Masson, P. Delecluse, S. Gualdi, A. Navarra, and T. Yamagata, 2005: Paramount impact of the Indian Ocean dipole on the East African short rains: A CGCM study. J. Climate, 18, 4514-4530, doi:10.1175/JCLI3541.1.

,,,--- S. A. Rao, H. Sakuma, and T. Yamagata, 2006: A CGCM study on the interaction between IOD and ENSO. J. Climate, 19, 1688-1705, doi:10.1175/JCLI3797.1.

,-- , and T. Yamagata, 2008: Unusual IOD event of 2007. Geophys. Res. Lett., 35, L14S11, doi:10.1029/2008GL034122.

Behringer, D. W., M. Ji, and A. Leetmaa, 1998: An improved coupled model for ENSO prediction and implications for ocean initialization. Part I: The ocean data assimilation system. Mon. Wea. Rev., 126, 1013-1021, doi:10.1175/ 1520-0493(1998)126<1013:AICMFE > 2.0.CO;2.

Bjerknes, J., 1964: Atlantic air-sea interaction. Advances in Geophysics, Vol. 10, Academic Press, 1-82, doi:10.1016/ S0065-2687(08)60005-9.

Cai, W., and T. Cowan, 2013: Why is the amplitude of the Indian Ocean dipole overly large in CMIP3 and CMIP5 climate models? Geophys. Res. Lett., 40, 1200-1205, doi:10.1002/grl.50208.

- , H. Hendon, and G. Meyers, 2005: Indian Ocean dipole-like variability in the CSIRO Mark 3 coupled climate model. J. Climate, 18, 1449-1468, doi:10.1175/JCLI3332.1.

— , T. Cowan, and M. Raupach, 2009: Positive Indian Ocean dipole events precondition southeast Australia bushfires. Geophys. Res. Lett., 36, L19710, doi:10.1029/2009GL039902.

Chan, S. C., S. K. Behera, and T. Yamagata, 2008: Indian Ocean Dipole influence on South American rainfall. Geophys. Res. Lett., 35, L14S12, doi:10.1029/2008GL034204.

Dee, D. P., and Coauthors, 2011: The ERA-Interim reanalysis: Configuration and performance of the data assimilation system. Quart. J. Roy. Meteor. Soc., 137, 553-597, doi:10.1002/qj.828.

Doi, T., S. K. Behera, and T. Yamagata, 2016: Improved seasonal prediction using the SINTEX-F2 coupled model. J. $A d v$. Model. Earth Syst., 8, 1847-1867, doi:10.1002/2016MS000744.

Enomoto, T., B. J. Hoskins, and Y. Matsuda, 2003: The formation of the Bonin high in August. Quart. J. Roy. Meteor. Soc., 129, 157-178, doi:10.1256/qj.01.211.

Feng, R., W. Duan, and M. Mu, 2017: Estimating observing locations for advancing beyond the winter predictability barrier of 
Indian Ocean dipole event predictions. Climate Dyn., 48, 1173-1185, doi:10.1007/s00382-016-3134-3.

Fichefet, T., and M. A. Morales Maqueda, 1997: Sensitivity of a global sea ice model to the treatment of ice thermodynamics and dynamics. J. Geophys. Res., 102, 12 609-12 646, doi:10.1029/ 97JC00480.

Fujii, Y., and Coauthors, 2015: Evaluation of the Tropical Pacific Observing System from the ocean data assimilation perspective. Quart. J. Roy. Meteor. Soc., 141, 2481-2496, doi:10.1002/ qj. 2579.

Good, S. A., M. J. Martin, and N. A. Rayner, 2013: EN4: Quality controlled ocean temperature and salinity profiles and monthly objective analyses with uncertainty estimates. J. Geophys. Res. Oceans, 118, 6704-6716, doi:10.1002/ 2013JC009067.

Gouretski, V., and F. Reseghetti, 2010: On depth and temperature biases in bathythermograph data: Development of a new correction scheme based on analysis of a global ocean database. Deep-Sea Res. I, 57, 812-833, doi:10.1016/ j.dsr.2010.03.011.

Gualdi, S., A. Navarra, E. Guilyardi, and P. Delecluse, 2003a: Assessment of the tropical Indo-Pacific climate in the SINTEX CGCM. Ann. Geophys., 46, 1-26, doi:10.4401/ ag-3385.

_ E. Guilyardi, A. Navarra, S. Masina, and P. Delecluse, 2003b: The interannual variability in the tropical Indian Ocean as simulated by a CGCM. Climate Dyn., 20, 567-582, doi:10.1007/s00382-002-0295-Z.

Guan, Z., and T. Yamagata, 2003: The unusual summer of 1994 in East Asia: IOD teleconnections. Geophys. Res. Lett., 30, 1544, doi:10.1029/2002GL016831.

Guilyardi, E., P. Delecluse, S. Gualdi, and A. Navarra, 2003: Mechanisms for ENSO phase change in a coupled GCM. J. Climate, 16, 1141-1158, doi:10.1175/1520-0442(2003)16<1141: MFEPCI $>2.0 . \mathrm{CO} ; 2$.

Hashizume, H., L. F. Chaves, and N. Minakawa, 2012: Indian Ocean dipole drives malaria resurgence in East African highlands. Sci. Rep., 2, 269, doi:10.1038/srep00269.

Hendon, H. H., and G. Wang, 2010: Seasonal prediction of the Leeuwin Current using the POAMA dynamical seasonal forecast model. Climate Dyn., 34, 1129-1137, doi:10.1007/ s00382-009-0570-3.

Horii, T., H. Hase, I. Ueki, and Y. Masumoto, 2008: Oceanic precondition and evolution of the 2006 Indian Ocean dipole. Geophys. Res. Lett., 35, L03607, doi:10.1029/2007GL032464.

Hosoda, S., T. Ohira, and T. Nakamura, 2008: A monthly mean dataset of global oceanic temperature and salinity derived from Argo float observations. JAMSTEC Rep. Res. Dev., 8, 47-59, doi:10.5918/jamstecr.8.47.

Iizuka, S., T. Matsuura, and T. Yamagata, 2000: The Indian Ocean SST dipole simulated in a coupled general circulation model. Geophys. Res. Lett., 27, 3369-3372, doi:10.1029/ 2000GL011484.

Izumo, T., and Coauthors, 2010: Influence of the state of the Indian Ocean dipole on following year's El Niño. Nat. Geosci., 3, 168-172, doi:10.1038/ngeo760.

Jia, L., and Coauthors, 2015: Improved seasonal prediction of temperature and precipitation over land in a high-resolution GFDL climate model. J. Climate, 28, 2044-2062, doi:10.1175/ JCLI-D-14-00112.1.

Jin, E. K., and Coauthors, 2008: Current status of ENSO prediction skill in coupled ocean-atmosphere models. Climate Dyn., 31, 647-664, doi:10.1007/s00382-008-0397-3.
Joseph, S., A. K. Sahai, B. N. Goswami, P. Terray, S. Masson, and J.-J. Luo, 2012: Possible role of warm SST bias in the simulation of boreal summer monsoon in SINTEX-F2 coupled model. Climate Dyn., 38, 1561-1576, doi:10.1007/ s00382-011-1264-1.

Kalnay, E., and Coauthors, 1996: The NCEP/NCAR 40-Year Reanalysis Project. Bull. Amer. Meteor. Soc., 77, 437-471, doi:10.1175/1520-0477(1996)077<0437:TNYRP>2.0.CO;2.

Keenlyside, N. S., M. Latif, M. Botzet, J. Jungclaus, and U. Schulzweida, 2005: A coupled method for initializing El Niño-Southern Oscillation forecasts using sea surface temperature. Tellus, 57A, 340-356, doi:10.1111/ j.1600-0870.2005.00107.x.

- - J. Jungclaus, L. Kornblueh, and E. Roeckner, 2008: Advancing decadal-scale climate prediction in the North Atlantic sector. Nature, 453, 84-88, doi:10.1038/nature06921.

Kirtman, B. P., and D. Min, 2009: Multi-model ensemble ENSO prediction with CCSM and CFS. Mon. Wea. Rev., 137, 2908-2930, doi:10.1175/2009MWR2672.1.

_ semble: Phase-1 seasonal-to-interannual prediction; phase-2 toward developing intraseasonal prediction. Bull. Amer. Meteor. Soc., 95, 585-601, doi:10.1175/BAMS-D-12-00050.1.

Kohyama, T., and T. Tozuka, 2016: Seasonal variability of the relationship between SST and OLR in the Indian Ocean and its implications for initialization in a CGCM with SST-nudging. J. Oceanogr., 72, 327-337, doi:10.1007/s10872-015-0329-x.

Kumar, A., M. Chen, and W. Wang, 2013: Understanding prediction skill of seasonal mean precipitation over the tropics. J. Climate, 26, 5674-5681, doi:10.1175/JCLI-D-12-00731.1.

- H. Wang, Y. Xue, and W. Wang, 2014: How much of monthly subsurface temperature variability in the equatorial Pacific can be recovered by the specification of sea surface temperatures? J. Climate, 27, 1559-1577, doi:10.1175/ JCLI-D-13-00258.1.

Liu, H., and Coauthors, 2017: Predictability of the Indian Ocean dipole in the coupled models. Climate Dyn., 48, 2005-2024, doi:10.1007/s00382-016-3187-3.

Luo, J.-J., S. Masson, S. Behera, S. Shingu, and T. Yamagata, 2005a: Seasonal climate predictability in a coupled OAGCM using a different approach for ensemble forecasts. J. Climate, $\mathbf{1 8}$ 4474-4497, doi:10.1175/JCLI3526.1.

- — E. E. Roeckner, G. Madec, and T. Yamagata, 2005b: Reducing climatology bias in an ocean-atmosphere CGCM with improved coupling physics. J. Climate, 18, 2344-2360, doi:10.1175/JCLI3404.1.

,-- S. Behera, and T. Yamagata, 2007: Experimental forecasts of the Indian Ocean dipole using a coupled OAGCM. J. Climate, 20, 2178-2190, doi:10.1175/JCLI4132.1.

_ S. Behera, Y. Masumoto, H. Sakuma, and T. Yamagata, 2008a: Successful prediction of the consecutive IOD in 2006 and 2007. Geophys. Res. Lett., 35, L14S02, doi:10.1029/ 2007 GL032793.

- S. Masson, S. Behera, and T. Yamagata, 2008b: Extended ENSO predictions using a fully coupled ocean-atmosphere model. J. Climate, 21, 84-93, doi:10.1175/2007JCLI1412.1.

— , R. Zhang, S. K. Behera, Y. Masumoto, F.-F. Jin, R. Lukas, and T. Yamagata, 2010: Interaction between El Niño and extreme Indian Ocean dipole. J. Climate, 23, 726-742, doi:10.1175/2009JCLI3104.1.

Madec, G., 2008: NEMO ocean engine, version 3.0. Note du Pôle de modélisation de l'Institut Pierre-Simon Laplace 27, Institut Pierre-Simon Laplace, 209 pp. 
— general circulation model reference manual. LODYC/ IPSL Tech. Rep. Note 11, 91 pp.

Masson, S., P. Terray, G. Madec, J. J. Luo, T. Yamagata, and K. Takahashi, 2012: Impact of intra-daily SST variability on ENSO characteristics in a coupled model. Climate Dyn., 39, 681-707, doi:10.1007/s00382-011-1247-2.

McPhaden, M. J., 1999: Genesis and evolution of the 1997-98 El Niño. Science, 283, 950-954, doi:10.1126/science.283.5404.950.

- 2004: Evolution of the 2002/03 El Niño. Bull. Amer. Meteor. Soc., 85, 677-695, doi:10.1175/BAMS-85-5-677.

_ , and Coauthors, 1998: The Tropical Ocean-Global Atmosphere observing system: A decade of progress. J. Geophys. Res., 103, 14 169-14240, doi:10.1029/97JC02906.

— Array for African-Asian-Australian Monsoon Analysis and Prediction. Bull. Amer. Meteor. Soc., 90, 459-480, doi:10.1175/ 2008BAMS2608.1.

Morioka, Y., V. J. Ratnam, W. Sasaki, and Y. Masumoto, 2013: Generation mechanism of the South Pacific subtropical dipole. J. Climate, 26, 6033-6045, doi:10.1175/JCLI-D-12-00648.1.

—, S. Masson, P. Terray, C. Prodhomme, S. K. Behera, and Y. Masumoto, 2014: Role of tropical SST variability on the formation of subtropical dipoles. J. Climate, 27, 4486-4507, doi:10.1175/JCLI-D-13-00506.1.

— , K. Takaya, S. K. Behera, and Y. Masumoto, 2015: Local SST impacts on the summertime Mascarene high variability. J. Climate, 28, 678-694, doi:10.1175/JCLI-D-14-00133.1.

Mulholland, D. P., P. Laloyaux, K. Haines, and M. Balmaseda, 2015: Origin and impact of initialization shocks in coupled atmosphere-ocean forecasts. Mon. Wea. Rev., 143, 4631-4644, doi:10.1175/MWR-D-15-0076.1.

Müller, W. A., H. Pohlmann, F. Sienz, and D. Smith, 2014: Decadal climate predictions for the period 1901-2010 with a coupled climate model. Geophys. Res. Lett., 41, 2100-2107, doi:10.1002/ 2014GL059259.

Nagura, M., W. Sasaki, T. Tozuka, J.-J. Luo, S. K. Behera, and T. Yamagata, 2013: Longitudinal biases in the Seychelles Dome simulated by 35 ocean-atmosphere coupled general circulation models. J. Geophys. Res., 118, 831-846, doi:10.1029/2012JC008352.

Nakamura, N., H. Kayanne, H. Iijima, T. R. McClanahan, S. Behera, and T. Yamagata, 2009: Mode shift in the Indian Ocean climate under global warming stress. Geophys. Res. Lett., 36, L23708, doi:10.1029/2009GL040590.

Navarra, A., and Coauthors, 2008: Atmospheric horizontal resolution affects tropical climate variability in coupled models. J. Climate, 21, 730-750, doi:10.1175/2007JCLI1406.1.

Nitta, T., 1987: Convective activities in the tropical western Pacific and their impact on the Northern Hemisphere summer circulation. J. Meteor. Soc. Japan, 65, 373-390, doi:10.2151/ jmsj1965.65.3_373.

Prodhomme, C., P. Terray, S. Masson, T. Izumo, T. Tozuka, and T. Yamagata, 2014: Impacts of Indian Ocean SST biases on the Indian monsoon: As simulated in a global coupled model. Climate Dyn., 42, 271-290, doi:10.1007/s00382-013-1671-6.

,,-- , G. Boschat, and T. Izumo, 2015: Oceanic factors controlling the Indian summer monsoon onset in a coupled model. Climate Dyn., 44, 977-1002, doi:10.1007/ s00382-014-2200-y.

Rao, S. A., and T. Yamagata, 2004: Abrupt termination of Indian Ocean dipole events in response to intra-seasonal oscillations. Geophys. Res. Lett., 31, L19306, doi:10.1029/2004GL020842.
— J.-J. Luo, S. K. Behera, and T. Yamagata, 2009: Generation and termination of Indian Ocean dipole events in 2003, 2006 and 2007. Climate Dyn., 33, 751-767, doi:10.1007/s00382-008-0498-z.

Reynolds, R. W., N. A. Rayner, T. M. Smith, D. C. Stokes, and W. Wang, 2002: An improved in situ and satellite SST analysis for climate. J. Climate, 15, 1609-1625, doi:10.1175/1520-0442 (2002)015<1609:AIISAS > 2.0.CO;2.

, T. M. Smith, C. Liu, D. B. Chelton, K. S. Casey, and M. G. Schlax, 2007: Daily high-resolution-blended analyses for sea surface temperature. J. Climate, 20, 5473-5496, doi:10.1175/ 2007JCLI1824.1.

Rodwell, M. J., and B. J. Hoskins, 1996: Monsoons and the dynamics of deserts. Quart. J. Roy. Meteor. Soc., 122, 1385-1404, doi:10.1002/qj.49712253408.

Roeckner, E., and Coauthors, 1996: The atmospheric general circulation model ECHAM-4: Model description and simulation of present-day climate. Max-Planck-Institut für Meteorologie Rep. 218, 90 pp.

— , and Coauthors, 2003: The atmospheric general circulation model ECHAM5. Part I: Model description. MPI-Rep. 349, Max-Planck-Institut für Meteorologie, Hamburg, Germany, 140 pp. [Available online at https://www.mpimet.mpg.de/ fileadmin/publikationen/Reports/max_scirep_349.pdf.]

Saji, N. H., and T. Yamagata, 2003: Possible impacts of Indian Ocean dipole mode events on global climate. Climate Res., 25 , 151-169, doi:10.3354/cr025151.

_ B. N. Goswami, P. N. Vinayachandran, and T. Yamagata, 1999: A dipole mode in the tropical Indian Ocean. Nature, 401, 360-363.

Sasaki, W., K. J. Richards, and J.-J. Luo, 2012: Role of vertical mixing originating from small vertical scale structures above and within the equatorial thermocline in an OGCM. Ocean Modell., 57-58, 29-42, doi:10.1016/j.ocemod.2012.09.002.

$\_, \ldots$, and _ 2013a: Impact of vertical mixing induced by small vertical scale structures above and within the equatorial thermocline on the tropical Pacific in a CGCM. Climate Dyn., 41, 443-453, doi:10.1007/s00382-012-1593-8.

, J.-J. Luo, and S. Masson, 2013b: Tropical cyclone simulation in a high-resolution atmosphere-ocean coupled general circulation model. Cyclones: Formation, Triggers and Control, K. Oouchi and H. Fudeyasu, Eds., Nova Science Publishers, 197-220.

_, T. Doi, K. J. Richards, and Y. Masumoto, 2014: Impact of the equatorial Atlantic sea surface temperature on the tropical Pacific in a CGCM. Climate Dyn., 43, 2539-2552, doi:10.1007/ s00382-014-2072-1.

,--1, and -2015 : The influence of ENSO on the equatorial Atlantic precipitation through the Walker circulation in a CGCM. Climate Dyn., 44, 191-202, doi:10.1007/ s00382-014-2133-5.

Schott, F. A., S.-P. Xie, and J. P. McCreary Jr., 2009: Indian Ocean circulation and climate variability. Rev. Geophys., 47, RG1002, doi:10.1029/2007RG000245.

Shi, L., H. H. Hendon, O. Alves, J.-J. Luo, M. Balmaseda, and D. Anderson, 2012: How predictable is the Indian Ocean dipole? Mon. Wea. Rev., 140, 3867-3884, doi:10.1175/ MWR-D-12-00001.1.

Song, Q., G. A. Vecchi, and A. J. Rosati, 2008: Predictability of the Indian Ocean sea surface temperature anomalies in the GFDL coupled model. Geophys. Res. Lett., 35, L02701, doi:10.1029/ 2007 GL031966.

Storto, A., S. Dobricic, S. Masina, and P. Di Pietro, 2011: Assimilating along-track altimetric observations through local 
hydrostatic adjustment in a global ocean variational assimilation system. Mon. Wea. Rev., 139, 738-754, doi:10.1175/ 2010MWR3350.1.

— S. Masina, and S. Dobricic, 2014: Estimation and impact of nonuniform horizontal correlation length scales for global ocean physical analyses. J. Atmos. Oceanic Technol., 31, 2330 2349, doi:10.1175/JTECH-D-14-00042.1.

Takaya, K., and H. Nakamura, 2001: A formulation of a phase-independent wave-activity flux for stationary and migratory quasigeostrophic eddies on a zonally varying basic flow. J. Atmos. Sci., 58, 608-627, doi:10.1175/ 1520-0469(2001)058<0608:AFOAPI >2.0.CO;2.

Takaya, A., Y. Morioka, and S. K. Behera, 2014: Role of climate variability in the heatstroke death rates of Kanto region in Japan. Sci. Rep., 4, 5655, doi:10.1038/srep05655.

Tanizaki, C., T. Tozuka, T. Doi, and T. Yamagata, 2017: Relative importance of the processes contributing to the development of SST anomalies in the eastern pole of the Indian Ocean Dipole and its implication for predictability. Climate Dyn., 49, 1289-1304, doi:10.1007/s00382-016-3382-2.

Terray, P., K. Kamala, S. Masson, G. Madec, A. K. Sahai, J.-J. Luo, and T. Yamagata, 2012: The role of the intra-daily SST variability in the Indian monsoon variability and monsoonENSO-IOD relationships in a global coupled model. Climate Dyn., 39, 729-754, doi:10.1007/s00382-011-1240-9.

Tozuka, T., T. Yokoi, and T. Yamagata, 2010: A modeling study of interannual variations of the Seychelles Dome. J. Geophys. Res., 115, C04005, doi:10.1029/2009JC005547.

Valcke, S., L. Terray, and A. Piacentini, 2000: The OASIS coupler user guide version 2.4. CERFACS Tech. Rep. TR/CGMC/00-10, 85 pp.

—, A. Caubel, R. Vogelsang, and D. Declat, 2004: OASIS3 Ocean Atmosphere Sea Ice Soil user's guide. CERFACS Tech. Rep. TR/CMGC/04/68, 70 pp.

Vecchi, G. A., and Coauthors, 2014: On the seasonal forecasting to regional tropical cyclone activity. J. Climate, 27, 7994-8016, doi:10.1175/JCLI-D-14-00158.1.

Wajsowicz, R. C., 2005: Potential predictability of tropical Indian Ocean SST anomalies. Geophys. Res. Lett., 32, L24702, doi:10.1029/2005GL024169.

_ 2 2007: Seasonal-to-interannual forecasting of tropical Indian Ocean sea surface temperature anomalies: Potential predictability and barriers. J. Climate, 20, 3320-3343, doi:10.1175/ JCLI4162.1.

Webster, P. J., A. Moore, J. Loschnigg, and M. Leben, 1999: Coupled ocean-atmosphere dynamics in the Indian Ocean during 1997-98. Nature, 401, 356-360, doi:10.1038/43848.

Xie, P., and P. A. Arkin, 1997: Global precipitation: A 17-year monthly analysis based on gauge observations, satellite estimates, and numerical model outputs. Bull. Amer. Meteor. Soc., 78, 2539-2558, doi:10.1175/1520-0477(1997)078<2539:GPAYMA>2.0.CO;2.
Yamagata, T., S. Behera, J.-J. Luo, S. Masson, M. Jury, and S. A. Rao, 2004: Coupled ocean-atmosphere variability in the tropical Indian Ocean. Earth's Climate: The Ocean-Atmosphere Interaction, Geophys. Monogr., Vol. 147, Amer. Geophys. Union, 189-212.

— - Y. Morioka, and S. K. Behera, 2016: Old and new faces of climate variations. Indo-Pacific Climate Variability and Predictability, S. K. Behera and T. Yamagata, Eds., World Scientific Series on Asia-Pacific Weather and Climate, Vol. 7, World Scientific, 1-23.

Yang, Y., S.-P. Xie, L. Wu, Y. Kosaka, N.-C. Lau, and G. A. Vecchi, 2015: Seasonality and predictability of the Indian Ocean dipole mode: ENSO forcing and internal variability. J. Climate, 28, 8021-8036, doi:10.1175/JCLI-D-15-0078.1.

Yokoi, T., T. Tozuka, and T. Yamagata, 2008: Seasonal variation of the Seychelles Dome. J. Climate, 21, 3740-3754, doi:10.1175/ 2008JCLI1957.1.

,-- , and -2012 : Seasonal and interannual variations of the SST above the Seychelles Dome. J. Climate, 25, 800-814, doi:10.1175/JCLI-D-10-05001.1.

Yuan, C., and T. Yamagata, 2015: Impacts of IOD, ENSO and ENSO Modoki on the Australian winter wheat yields in recent decades. Sci. Rep., 5, 17252, doi:10.1038/srep17252.

_- T. Tozuka, T. Miyasaka, and T. Yamagata, 2009: Respective influences of IOD and ENSO on the Tibetan snow cover in early winter. Climate Dyn., 33, 509-520, doi:10.1007/ s00382-008-0495-2.

Yuan, D., and Coauthors, 2011: Forcing of the Indian Ocean dipole on the interannual variations of the tropical Pacific Ocean: Roles of the Indonesian Throughflow. J. Climate, 24, 35933608, doi:10.1175/2011JCLI3649.1.

Zhao, M., and H. H. Hendon, 2009: Representation and prediction of the Indian Ocean dipole in the POAMA seasonal forecast model. Quart. J. Roy. Meteor. Soc., 135, 337-352, doi:10.1002/ qj. 370 .

Zhu, J., B. Huang, A. Kumar, and J. L. Kinter III, 2015a: Seasonality in prediction skill and predictable pattern of tropical Indian Ocean SST. J. Climate, 28, 7962-7984, doi:10.1175/ JCLI-D-15-0067.1.

, and Coauthors, 2015b: ENSO prediction in Project Minerva: Sensitivity to atmospheric horizontal resolution and ensemble size. J. Climate, 28, 2080-2095, doi:10.1175/ JCLI-D-14-00302.1.

— A. Kumar, H. Wang, and B. Huang, 2015c: Sea surface temperature predictions in NCEP CFSv2 using a simple ocean initialization scheme. Mon. Wea. Rev., 143, 3176-3191, doi:10.1175/MWR-D-14-00297.1.

, - - H.-C. Lee, and H. Wang, 2017: Seasonal predictions using a simple ocean initialization scheme. Climate Dyn., doi:10.1007/s00382-017-3556-6, in press. 